\title{
Numerical simulation and evaluation of spacer-filled direct contact membrane distillation module
}

\author{
Khadije El Kadi $^{1} \cdot$ Isam Janajreh ${ }^{1}$ (D) $\cdot$ Raed Hashaikeh $^{2}$
}

Received: 17 March 2019 / Accepted: 17 June 2020 / Published online: 29 June 2020

(c) The Author(s) 2020

\begin{abstract}
Membrane fouling and temperature polarization are the most common issues that cause limitations to membrane distillation (MD) process. Integration of spacers has been proven to resolve those problems by inducing regions of turbulence and giving the required mechanical support to the membrane. In this work, a robust high-fidelity computational fluid dynamics simulation is carried out to assess and quantify the performance of spacer-filled DCMD module and compare it with a baseline spacer-free DCMD module. Mainly, simulations are done to delineate the problem of concentration polarization and by alternating spacers material with different thermal conductivities and different displacement configurations. The performance of these different models is demonstrated in terms of concentration boundary layer development, temperature distributions, temperature polarization coefficient (TPC), mass flux, heat flux, heat transfer coefficient, and thermal efficiency. Results show that concentration polarization can penalize mass flux by nearly $10 \%$, and conductive spacers have favorable effect on the DCMD performance compared to spacer-free in terms of TPC by $50 \%$, mass flux by $35 \%$, heat flux by $31 \%$, thermal efficiency by $1 \%$, and top and bottom membrane surface heat transfer coefficients of, respectively, $19 \%$ and $62 \%$. Meanwhile, the stride of the spacers in the range of $1.5-3.5 \mathrm{~mm}$ tends to achieve a measurable mass flux. Generally, spacers integration has confirmed the capability of reducing concentration polarization at the membrane surface. These attained improvements will accelerate industrial deployments of MD.
\end{abstract}

Keywords CFD $\cdot$ Membrane distillation $\cdot$ Spacers $\cdot$ Temperature polarization $\cdot$ Permeation flux $\cdot$ Membrane fouling

\section{Introduction}

Due to water and energy scarcity, low-energy desalination technologies have gained more attention recently (Winter 2014; Huffman 2014). Water separation using membrane distillation (MD) has been risen as the lowest driving energy when compared to other membrane-based processes (e.g., reverse osmosis (RO), ultrafiltration (UF), etc.) (Ashoor et al. 2016; Khayet 2011). In contrast to these conventional isothermal membrane-based processes, MD is thermally driven and is operating at a temperature range of $\left(40-80^{\circ} \mathrm{C}\right)$

Isam Janajreh

Isam.Janajreh@ku.ac.ae

1 Mechanical Engineering Department, Center for Membrane and Advanced Water Technology, Khalifa University of Science and Technology, PO Box 54224, Masdar City Campus, Abu Dhabi, UAE

2 Chemical Engineering Department, New York University, Abu Dhabi, Abu Dhabi, UAE
(Khayet 2011; Khayet and Matsuura 2011a). The working principle of MD employs a non-wetted hydrophobic porous membrane sandwiched between two thin channels, i.e., a warm saline feed and a cooler permeate (typically fresh water). The simplest configuration of MD is having both channels in direct contact with the membrane as illustrated in Fig. 1 and is nominally known as direct contact membrane distillation (DCMD). The resulting temperature difference across the membrane creates a partial pressure gradient which consequently initiates fresh water vapor transport from feed side to permeate side throughout the membrane's dry pores. Although MD operates at atmospheric conditions, precaution should be considered to obtain a reliable fouling resistant. This can be done by membrane surface coating or feed pre-treatment (Wang and Lin 2017; Warsinger et al. 2015; Razmjou et al. 2012). Nevertheless, a more robust solution is providing the membrane with an additional mechanical support by integrating spacers on both top and bottom membrane surfaces as depicted in Fig. 2 (Warsinger et al. 2015; Khayet and Matsuura 2011b). Fortunately, it has 


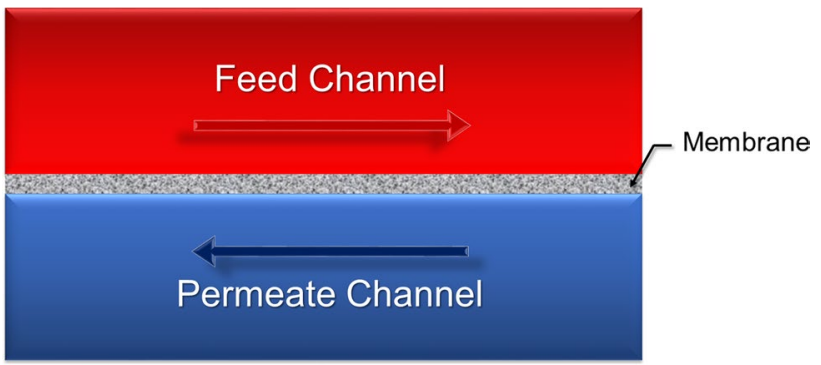

Fig. 1 Schematic of direct contact membrane distillation (DCMD) under counter flow configuration

been proven that such supportive mesh could contribute to better performance by introducing regions of turbulence flow near the membrane boundary layer (Warsinger et al. 2015; Janajreh et al. 2017a; Phattaranawik et al. 2001; MartinezDíez et al. 1998). This localized turbulence tends to reduce polarization effects of both temperature and concentration at membrane surfaces leading to a higher transmembrane temperature difference or lower near surface brine concentration which reverts to offer a great potential for system optimization (Albeirutty et al. 2018; Martinez-Diez and Vazguez-Gonzalez 1999). Hence, many researchers refer to spacers as "turbulence promoters" (Popović et al. 2013; Yang et al. 2012).

The quantification of the flux due to the integration of spacer has not been studied thoroughly in the literature despite the numerous experimental and simulation works that have been sought by several researchers to gain more insight into its operation (Phattaranawik et al. 2001; Martínez-Díez et al. 1998; Albeirutty et al. 2018; Yang et al. 2012; Hagedorn et al. 2017; Martínez and Rodríguez-Maroto 2006; Taamneh and Bataineh 2017; Tamburini et al. 2016; Katsandri 2017a, b; Chang et al. 2015, 2017; Al-Sharif et al. 2013; Shakaib et al. 2012; Seo et al. 2017; Ahmed et al. 2017). Recently, Albeirutty et al. (2018) have investigated experimentally the flow dynamics and heat transport across a spacer-filled MD channels under different attack and filament angles. Maximum performance in terms of highest heat transfer coefficient was recorded at a symmetrical attack angle of $45^{\circ}$ and filament angle of $90^{\circ}$. Also, increasing the spacers filament angle above $90^{\circ}$ was found to increase the pressure drop across the channels and therefore inferior the performance (Albeirutty et al. 2018). The angle of attack refers to the angle made between the flow direction and spacer orientation, whereas the filament angle refers to the orientation of two spacers stacked on top of each other forming a mesh. For instance, the illustrated spacerfilled MD channel in Fig. 2 is oriented at angle of attack and at filament angle both of $90^{\circ}$. Hagedorn et al. (2017), however, have proposed a combined pressure drop and heat transfer correlation to evaluate the performance under different types of commercial spacers with different hydraulic diameters. The experiments were conducted at the same flow conditions, where it was shown that thicker spacer results in a better system performance in terms of lowest pressure drop of $0.037 \mathrm{bar} / \mathrm{m}$ and highest heat transfer coefficient of $5087 \mathrm{~W} / \mathrm{m}^{2} \mathrm{~K}$ (Hagedorn et al. 2017). Earlier MartínezDíez et al. (1998) and Martínez and Rodríguez-Maroto (2006) have studied experimentally the mass flux enhancement of a spacer-filled DCMD module when compared to a spacer-free module, where mass flux was predicted using a validated Knudsen/molecular transport model. Coarse nettype spacers with the diameter of $0.25 \mathrm{~mm}$ were used and placed at attack and filament angles both of $90^{\circ}$. At identical flow conditions (i.e., parallel flow, flow velocity of $0.3 \mathrm{~m} / \mathrm{s}$, saline feed of $2 \mathrm{M}$ concentration, and bulk temperature difference of $30^{\circ} \mathrm{C}$ ), mass flux has been enhanced by a factor of $\sim 1.65$ using the spacer-filled DCMD module (Martínez and Rodríguez-Maroto 2006). Similar study has been also conducted by Phattaranawik et al. (2001), where two types of spacers (i.e., coarse with the diameter of $1.15 \mathrm{~mm}$, and fine with the diameter of $0.55 \mathrm{~mm}$ ) were employed and resulted in $31-41 \%$ average mass flux gain compared to spacer-free module.

On the other hand, Taamneh and Bataineh (2017) have investigated the flow properties under several spacers

Fig. 2 Simple illustration of a spacer-filled DCMD channels

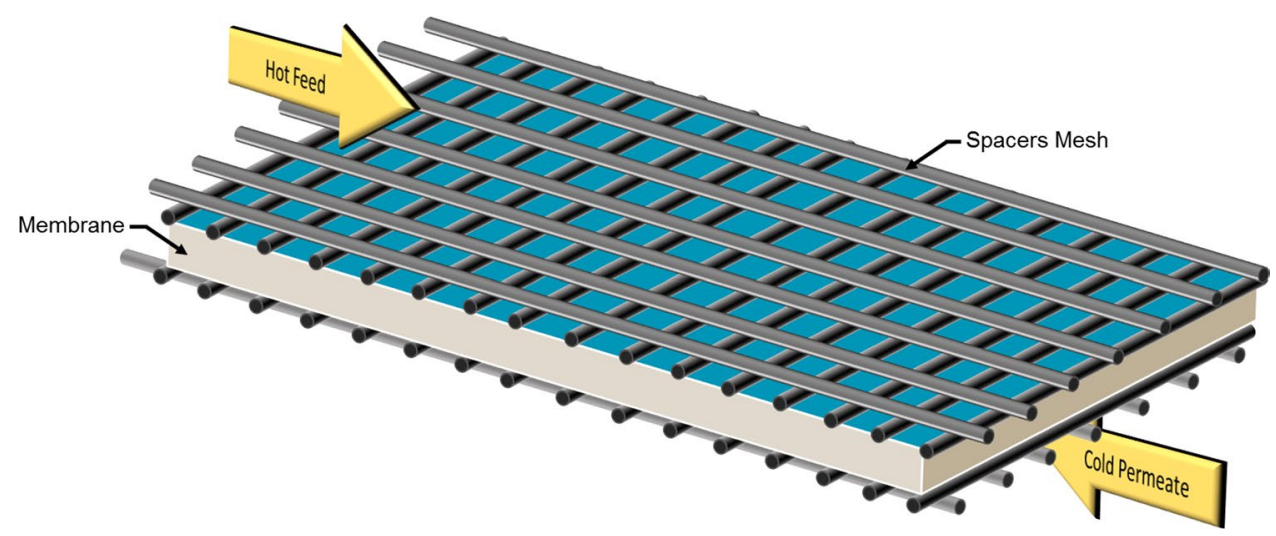


filament angle using a validated 3-D computational fluid dynamics (CFD) model of DCMD. A dimensionless quantification of pressure difference in terms of drag coefficient and Darcy friction factor were used to experimentally validate the model. The model showed that heat transfer (or Nusselt number) can reach the double when using spacerfilled DCMD channels compared to the spacer-free model (Taamneh and Bataineh 2017). Tamburini et al. (2016) have also developed a 3-D model using direct numerical simulation (DNS) of a spacer-filled MD channels to study their effect on local heat transfer. Experimental validation of surface Nusselt number was done using two spacer-filled channels separated by a polycarbonate layer. They found that the highest average Nusselt number (i.e., 26.2) was obtained with spacers oriented at $45^{\circ}$ with the flow channel. Furthermore, Katsandri (2017a, b) have developed an experimentally validated 3-D CFD model of a spacer-filled flat sheet DCMD. Assuming fully permeable membrane and introducing heat and mass fluxes as an additional fixed source to the system's governing equations (i.e., continuity and energy equations), velocity, shear stress, and temperature polarization distributions were analyzed at different attack angles. It was found that the best spacer orientation was at attack angle of $45^{\circ}$ reaching a superior MD performance of mass flux of $100.33 \mathrm{~kg} / \mathrm{m}^{2} \mathrm{~h}$ and heat transfer coefficient of 11,044-11,927 W/m² K. Similar work was done earlier by (Chang et al. 2015, 2017). Using spacer diameter of $3 \mathrm{~mm}$, the model was capable to compare flow pattern and system performance under two different spacer orientations. Elevated TPC, mass flux, and heat transfer coefficient values were around $0.9,25 \mathrm{~kg} / \mathrm{m}^{2} \mathrm{~h}$, and $15,000 \mathrm{~W} / \mathrm{m}^{2} \mathrm{~K}$, respectively, compared to spacer-free of around $0.45,17 \mathrm{~kg} / \mathrm{m}^{2} \mathrm{~h}$, and $2400 \mathrm{~W} / \mathrm{m}^{2} \mathrm{~K}$, respectively. Al-Sharif et al. (2013) have developed a similar 3 -D model under hard assumptions. The model simulated three different spacer geometries; however, no validation with any experimental work was reported. Spacers configured in three stacked layers were found to have the lowest pressure drop $(-0.346 \mathrm{kPa} / \mathrm{m})$ across the channels which reflected in producing symmetrical temperature profiles when compared to other geometries. A 2-D CFD model of flat sheet DCMD was also developed by Shakaib et al. (2012), and the model concentrated on the role of seven different spacers orientations on temperature polarization effect. Yang et al. (2012) have carried different geometric sensitivity studies on the integration of baffles and spacers using a validated 3-D symmetrical CFD model of a hollow fiber MD module. The best performance has been recorded when integrating baffles and quad spacers simultaneously to the channels. This model, however, was validated using the average mass flux and the pressure drop across the channels with no reference to temperature distribution. Nonetheless, Seo et al. (2017) have developed a spacer design optimization strategy that involves fifty-one different spacers designs compromising several configurations (i.e., submerged, cavity, and zigzag), filaments shapes (i.e., circles, rectangles, and triangles), and symmetricity variation targeting optimal design with the lowest possible temperature and concentration polarization effects. These studies were carried out using a 2-D CFD model of DCMD where the average mass flux was validated experimentally. The solution was sought via the commercial COMSOL software. Symmetric circular-zigzag configuration marked the best performance with $26 \%$ gain in the average mass flux compared to the spacer-free model.

Despite the abundant researches done on spacer-filled MD systems and their orientation and geometry effect on heat and mass transfer, advanced studies have appeared recently on the role of spacers material on membrane fouling (Abid et al. 2017a). Surface coating modification of polymeric spacers using metallic particles as copper (Hausman 2011; Araújo et al. 2012; Richard et al. 2009), silver (Araújo et al. 2012; Yang et al. 2009; Ronen et al. 2015), and gold (Araújo et al. 2012) was investigated to reduce membrane biofouling impact. As a result, this modification is found to provide higher and steadier permeate flux when compared to unmodified spacers (Yang et al. 2009; Ronen et al. 2015). In long-term process, surface modification is highly subjected to degradation and therefore leads to unsustainable anti-fouling (Habimana et al. 2014). On the other hand, application of electrical potentials to spacers of electrically conductive material is also a promising anti-fouling strategy (Abid et al. 2017a; Baek et al. 2014). In this method, metallic spacers [e.g., titanium (Baek et al. 2014; Abid et al. 2017b)] are charged periodically and used as electrodes when fouling occurs within the process. Consequently, oxidation of foulants occurs at the membrane-feed interface allowing a noticeable recovery of permeate flux. Meanwhile, the effect of using neutral metallic spacers as a thermally conductive material on the temperature distribution across the DCMD channels was not spotted in the literature except for the previous work of the authors (Ahmed et al. 2017), where typically polymeric spacers are the most referred in the literature. The previous study, however, was incomprehensive as it was carried using a non-practical model geometry of $2 \mathrm{~cm}$. In the current study, an extension on the previous work is done where a more robust 2-D validated CFD model of spacer-filled DCMD is developed to carry different spacers (or filament) material of alternatively polymer or copper based. The geometry of the current model is more reasonable. Investigation of the effect of increasing the distance between tandem spacers is also done. The performance of the spaced models is compared with a spacer-free model in terms of mass flux, temperature polarization coefficient (TPC), thermal efficiency, and surface heat transfer coefficient. 


\section{Methodology}

\section{Model setup and development}

In this work, a numerical study will be developed on spacer-filled DCMD module using non-isothermal computational fluid dynamics (CFD) model governed by Navier-Stokes equations and thermally coupled with the porous membrane. The two-dimensional (2-D) computational domain of the DCMD baseline model consists of two channels (i.e., feed and permeate) at $210 \mathrm{~mm}$ length by 1 $\mathrm{mm}$ height where a 130- $\mu \mathrm{m}$-thick membrane is inserted/ sandwished between them and is illustrated in Fig. 3a. A modified model with spacer-filled channels having a filament diameter of $0.5 \mathrm{~mm}$ and a shortest distance between two consecutive filaments set to $1.5 \mathrm{~mm}$ distributed equally at both top and bottom membrane surfaces is also shown in Fig. 3b. Suitable flow conditions will be applied for both channels arranged in a counter-current flow maintained at laminar regime with a given inlet velocity of $0.1 \mathrm{~m} / \mathrm{s}$ (or Reynolds number ( $\mathrm{Re}$ ) of 100), feed inlet temperature of $75^{\circ} \mathrm{C}$, and permeate inlet temperature of $25^{\circ} \mathrm{C}$. Such flow conditions seem to provide a reasonable performance as per the previous work of authors (Janajreh et al. 2017a, b).

The flow can be described and governed by a planar 2-D, steady, and incompressible system of Navier-Stokes coupled with the energy equation to capture the fluid and the membrane temperature variations. System of continuity, $x$ - and $y$-momentum, and energy equations are represented as (Eqs. 1-4):

- Continuity:

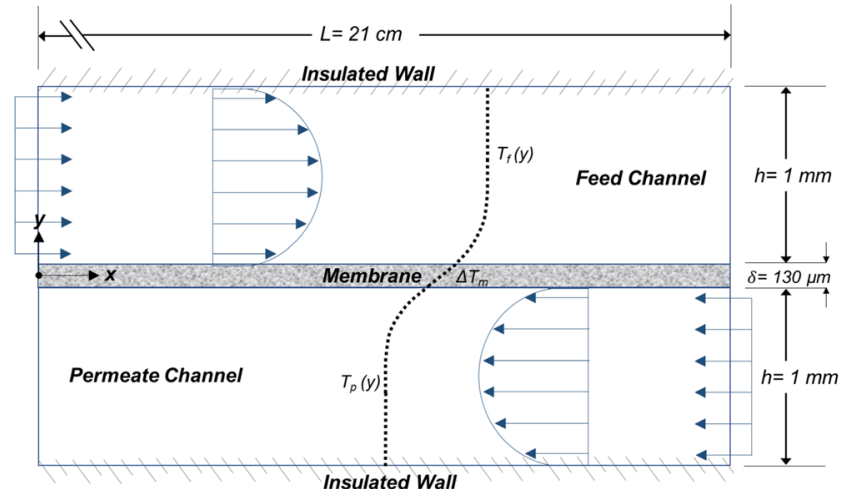

(a) Spacer-free channels (baseline) $\frac{\partial \rho u}{\partial x}+\frac{\partial \rho v}{\partial y}=0$

- $x$-Momentum:

$\frac{u \partial \rho u}{\partial x}+\frac{v \partial \rho u}{\partial y}=-\frac{\partial P}{\partial x}+\mu\left(\frac{\partial^{2} u}{\partial x^{2}}+\frac{\partial^{2} u}{\partial y^{2}}\right)$

- $y$-Momentum:

$\frac{u \partial \rho v}{\partial x}+\frac{v \partial \rho v}{\partial y}=-\frac{\partial P}{\partial y}+\mu\left(\frac{\partial^{2} v}{\partial x^{2}}+\frac{\partial^{2} v}{\partial y^{2}}\right)+\rho g_{y}$

- Energy:

$\frac{u \partial \rho C_{p} T}{\partial x}+\frac{v \partial \rho C_{p} T}{\partial y}=k\left(\frac{\partial^{2} T}{\partial x^{2}}+\frac{\partial^{2} T}{\partial y^{2}}\right)+S_{\mathrm{h}}$

where $u$ and $v$ are, respectively, the $x$ - and $y$-velocity components, $P$ is the pressure, $g_{y}$ is the gravitational acceleration, $C_{p}$ is the specific heat capacity, $T$ is the temperature, $k$ is the thermal conductivity, and $S_{\mathrm{h}}$ is the additional heat sink/source terms which is in the case of DCMD attributed to the latent heat of evaporation at feed afterward released by condensation at permeate side.

A structured quadratic mesh is used for the geometry defined in Fig. 3 and is refined at top and bottom boundaries of each zone to enable capturing the kinetic and thermal boundary layers. Figure 4 shows the modified spacerfilled mesh consisting of 1,233,296 cells with minimum orthogonal quality of $4.08 \mathrm{E}-02$ and maximum aspect ratio of $6.935 \mathrm{E}+01$ indicating a highly refined mesh. The baseline spacer-free DCMD mesh, however, consists of 277,200 orthogonal computational cells with perfect orthogonal quality of 1 and maximum aspect ratio of $4.296 \mathrm{E}+01$. This

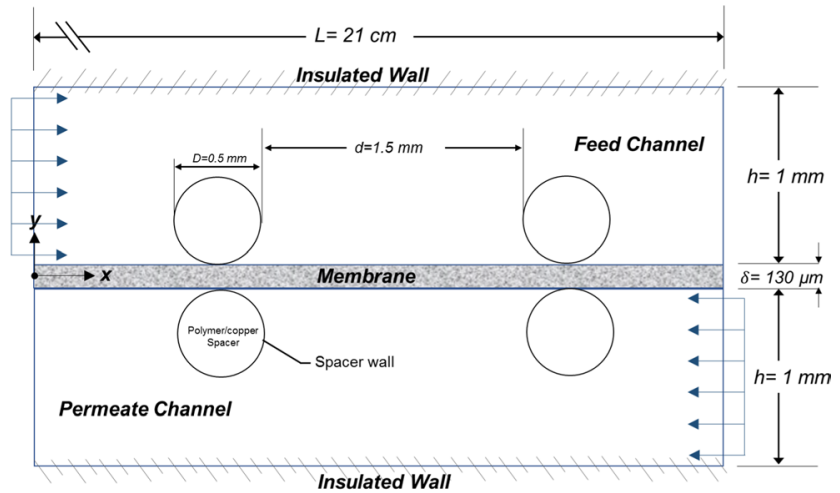

(b) Spacer-filled channels

Fig. 3 Schematic diagram of DCMD geometry, zones, and flow configuration of a spacer-free DCMD baseline model, and $\mathbf{b}$ spacer-filled DCMD model 


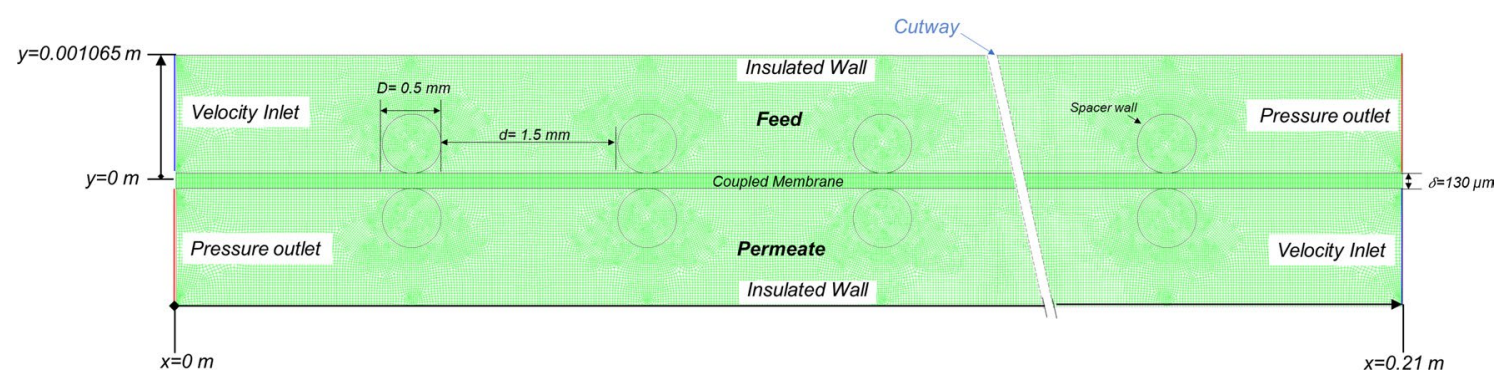

Fig. 4 Cut-way of spacer-filled DCMD computational domain and discretized mesh

baseline model was validated with experiments in the previous work of the authors (Janajreh et al. 2017b, c).

The flow is considered as steady where the boundary conditions are flow inlet Dirichlet (given velocity and temperature values) and outlet Neumann (zero velocity gradient and constant atmospheric pressure). Standard k-epsilon (k- $-\varepsilon$ ) turbulent model is activated to capture the localized turbulence around the spacers fixing the turbulent intensity at 5\% and turbulent viscosity ratio at 10 for the inlets and outlets of both channels. Stationary bulk, membrane, and spacers walls are subjected to no-slip and no-penetrating velocity condition $\left(V_{w}=0 \mathrm{~m} / \mathrm{s}\right)$. The channels outer walls are thermally insulated (zero heat flux), while internally the spacers and membrane walls are coupled with feed and permeate channels. The feed and permeate enter the domain at $R e=100$, i.e., $0.1 \mathrm{~m} / \mathrm{s}$, while thermally are at $75^{\circ} \mathrm{C}$ and $25^{\circ} \mathrm{C}$, respectively. Thermo-physical properties of the porous polyvinylidenefluoride (PVDF) membrane, the brine feed, and the fresh permeate are listed in Table 1. The model is developed within the Ansys/Fluent 16.2 environment which is based on finite volume method (FVM) and segregated solver. The semi-implicit method for pressure-linked equations (SIMPLE) algorithm is used for pressure-velocity coupling and the second-order upwind spatial derivatives for discretization of the conservation equations (i.e., momentum and energy). A tight computational tolerance on the residuals of
$10^{-15}$ was used to all the scalar equations (i.e., continuity, and $x$ - and $y$-momentums and energy).

\section{Spacers designs}

In this work, three analysis studies are carried out and the considered domains are those have been presented in numerous DCMD per previous work of the authors and other researcher, Janajreh et al. (2017a), Chang et al. (2015, 2017), Ahmed et al. (2017) and are summarized as follows:

1. The effect of different spacers materials on the DCMD performance is done first. It entails a comparison in the performance between a "non-conductive" and conductive spacer. The non-conductive spacers are set to be polymer based using identical thermo-physical properties of the polymeric PVDF membrane material, whereas copper material is selected for the conductive spacers case (see Table 1).

2. In the second study, modification on the spacer displacement is done by increasing the distance between two consecutive spacers. These models including 0,106 , and 53 distributed equally through the DCMD module length of $21 \mathrm{~cm}$. A schematic of the baseline and spacer cases is illustrated in Fig. 5 and is denoted as (a) BL, (b) D1.5, and (c) D3.5, respectively. The models were
Table 1 Thermo-physical properties of the materials used in the DCMD numerical model

\begin{tabular}{lllll}
\hline Material & Density $\left(\mathrm{kg} / \mathrm{m}^{3}\right)$ & $\begin{array}{l}\text { Specific heat } \\
(\mathrm{J} / \mathrm{kg} \mathrm{K})\end{array}$ & $\begin{array}{l}\text { Thermal conductiv- } \\
\text { ity }(\mathrm{W} / \mathrm{m} \mathrm{K})\end{array}$ & $\begin{array}{l}\text { Dynamic } \\
\text { viscosity } \\
(\mathrm{kg} / \mathrm{m} \mathrm{s})\end{array}$ \\
\hline PVDF (Iguchi et al. 2007) & 1175 & 1325 & 0.2622 & - \\
Water Vapor & 0.554 & 2014 & 0.0261 & - \\
Porous membrane $^{\mathrm{a}}$ & 302.2 & 1896.9 & 0.0662 & - \\
$\begin{array}{l}\text { Saline sea water } \\
\text { et al. 2010) }\end{array}$ & 1000.5 & 4022.8 & 0.642 & $4.145 \mathrm{E}-4$ \\
$\begin{array}{l}\text { Pure water } \\
\text { Copper }\end{array}$ & 998.2 & 4182 & 0.6 & - \\
\hline
\end{tabular}

${ }^{\mathrm{a}}$ Using weighted average

${ }^{\mathrm{b}}$ At $3.5 \%$ salinity and $75^{\circ} \mathrm{C}$

${ }^{\mathrm{c}}$ At $0 \%$ salinity and $25^{\circ} \mathrm{C}$ 
Fig. 5 Schematic diagram of the baseline (a) and two types of spacer-filled DCMD model with distance between two successive spacers of $\mathbf{b} 1.5 \mathrm{~mm}$ and $\mathbf{c}$ $3.5 \mathrm{~mm}$, respectively

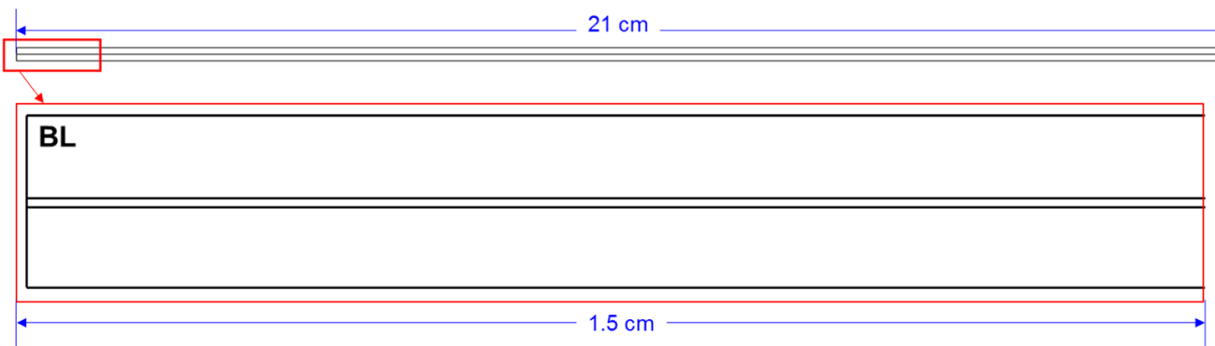

(a) Type: BL

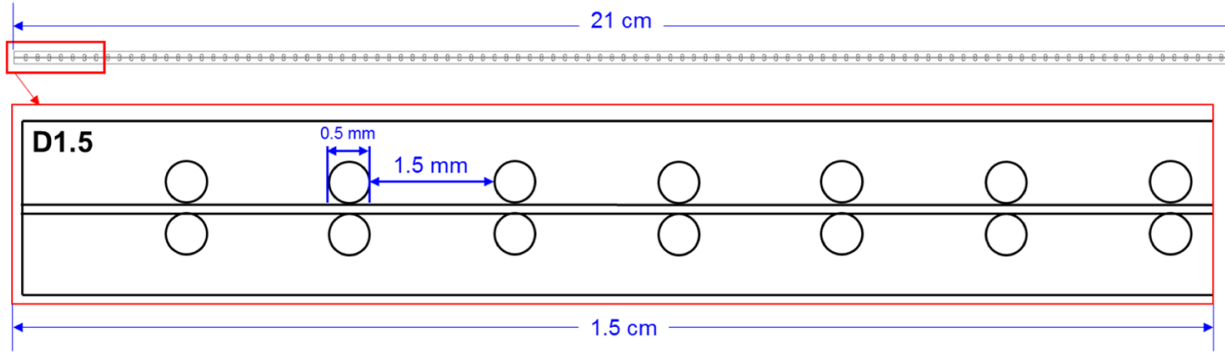

(b) Type: D1.5

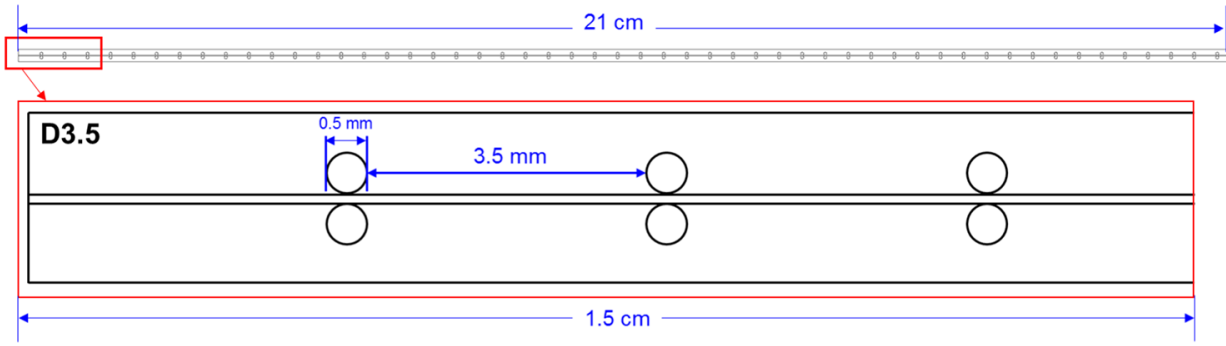

(c) Type: D3.5 solved, and consequently, their DCMD performance was evaluated and compared. Comparative evaluation between the baseline DCMD model in these two studies will be presented in terms of mass flux, TPC, thermal efficiency, and heat transfer coefficient.

3. Third study focuses on the influence of the spacers on concentration polarization and its localized distributions as this information is very difficult to obtain experimentally. Operation at high concentration can lead to salt accumulation, performance drop, and fouling. Therefore, information of both temperature and concentration distribution would be of a great help to avoid fouling since proper integrating of spacers could mitigate and remedy such problem. This has been done by modeling the feed side of both BL and D1.5 cases (see Fig. 5) with flow of two-species mixture of brine and fresh water and observing the variation of the brine specie spatially along and perpendicularly away from the membrane surface as fresh water species is transported out from that membrane surface.

\section{Performance metrics evaluation}

Because of the thermally coupled membrane, the temperature distribution at the top and bottom membrane surfaces is the most pronounced flow variable. As the temperature distribution and velocity fields are computed from the numerical model, system performance metrics including mass flux, TPC, heat flux, and thermal efficiency are evaluated subsequently using theoretical models to assess the DCMD performance.

\section{Mass transfer}

Due to temperature polarization, the saturated pressure gradient across membrane surfaces occurs and drives the mass 
transfer through the hydrophobic porous membrane. The general mass flux expression is as per the work of Chen and coworkers and is written as (Chen et al. 2009):

$J^{\prime \prime}=c_{\mathrm{m}}\left(P_{\mathrm{f}}^{\mathrm{sat}}-P_{\mathrm{p}}^{\mathrm{sat}}\right)$

where $c_{\mathrm{m}}$ is the membrane mass coefficient, $P_{\mathrm{f}}^{\mathrm{sat}}$ and $P_{\mathrm{p}}^{\text {sat }}$ are the saturated water vapor pressures at the feed and permeate membrane surface, respectively. The vapor pressure of pure water is related to the membrane surface temperature at the same side and is estimated using the Antoine equation (Blackshaw 1979) as:

$P_{\mathrm{p}}^{\mathrm{sat}}=\exp \left(23.1964-\frac{3815.44}{T_{\mathrm{m}, \mathrm{p}}-46.13}\right)$

where $T_{\mathrm{m}, \mathrm{p}}$ is the membrane surface temperature at the permeate side. Adjustment is required for the binary mixture as in the case of the feed side and per the work of Chen and others (Janajreh et al. 2017b; Chen et al. 2009; Janajreh and Suwwan 2014):

$P_{\mathrm{f}}^{\mathrm{sat}}=m_{\mathrm{w}} a_{\mathrm{w}} \exp \left(23.1964-\frac{3815.44}{T_{\mathrm{m}, \mathrm{f}}-46.13}\right)$

where $T_{\mathrm{m}, \mathrm{f}}$ is the membrane surface temperature at the feed side, $m_{\mathrm{w}}$ is the mole fraction of the water in saline solution, and $a_{\mathrm{w}}$ is the water activity in the feed mixture solution. In desalination application, water activity in $\mathrm{NaCl}$ solutions is estimated using the correlation equation of Lawson and Lloyd (1997) and Khayet (2011) and when using $m_{\mathrm{NaCl}}$ as the mole fraction of salt, the $a_{\mathrm{w}}$ is written as:

$a_{w}=1-\frac{m_{\mathrm{NaCl}}}{2}-10 m_{\mathrm{NaCl}}^{2}$
Three essential membrane mass coefficient models are stated in the literature to describe the mass transport across the porous membrane (Chen et al. 2009): (1) the Knudsen diffusion, (2) the Poiseuille flow, and (3) the molecular diffusion. Whereas many combinations of the three models were presented in the literature, dusty gas model (DGM) and KM-P model are common examples of combined models for predicting mass flux (Orfi and Loussif 2010). DGM combines Poiseuille flow model with diffusion models (Knudsen and molecular) in parallel configuration, whereas the KM-P model combines diffusion models in parallel configuration and added to them the Poiseuille flow model. At small pore size, the molecular diffusion model can be ignored without compromising the accuracy of the results (Chen et al. 2009). In this work, a simplification of the KM-P model is done by eliminating the molecular effect and combining both Knudsen and Poiseuille models in series following the work of Chen et al. (2009) and Seo et al. (2017). Figure 6 compares the DGM, KM-P, and the adopted K-P combined models. The modified K-P adopted model can be described as:

$c_{\mathrm{m}}=c_{\mathrm{K}}+c_{\mathrm{P}}=1.064 \alpha(T) \frac{\varepsilon r_{\mathrm{p}}}{\tau \delta_{\mathrm{m}}} \sqrt{\frac{M_{\mathrm{w}}}{R T_{\mathrm{m}}}}+0.125 \beta(T) \frac{\varepsilon r_{\mathrm{p}}^{2}}{\tau \delta_{\mathrm{m}}} \frac{M_{\mathrm{w}} P_{\mathrm{m}}}{R T_{\mathrm{m}} \mu_{\mathrm{v}}}$

where $\alpha(T)$ and $\beta(T)$ are the contribution of Knudsen and Poiseuille models, respectively, and are both selected to be unity in this study. $M_{\mathrm{w}}$ is the molecular weight of water, $T_{\mathrm{m}}$ is the mean membrane temperature, $R$ is the universal gas constant $(8.315 \mathrm{~J} / \mathrm{mol} \mathrm{K}), P_{\mathrm{m}}$ is the membrane mean pressure of partial pressures at top and bottom membrane surfaces found as per Eqs. 6 and 7, $\mu_{\mathrm{v}}$ is the gas viscosity, $r_{\mathrm{p}}$ is the pore radius, $\varepsilon$ is the membrane porosity, and finally $\tau$ is the tortuosity factor which is defined as the direct inverse of porosity in the case of polymer structures (Elias-Kohav
Fig. 6 Electrical analogy circuit representing different combination of mass transport models: a DGM, b KM-P, and the adopted in this work the $\mathbf{c} \mathrm{K}-\mathrm{P}$ model

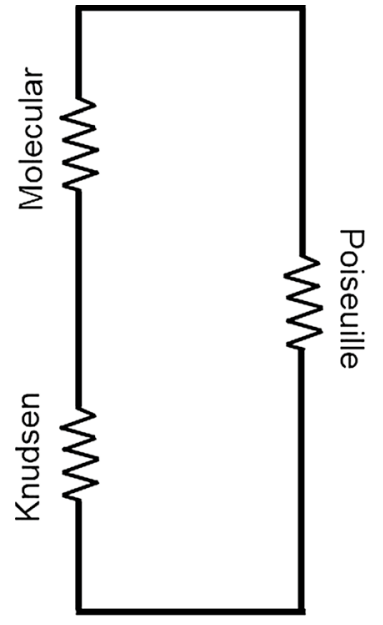

(a) DGM
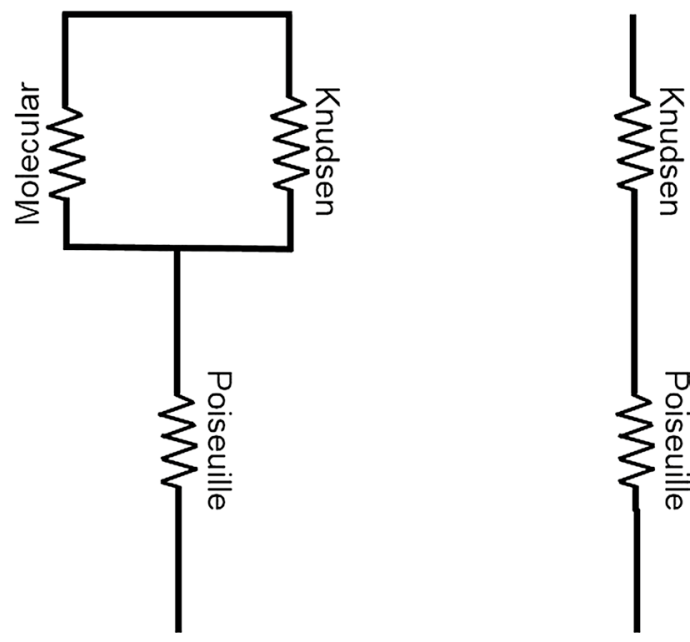

(b) KM-P

(c) K-P

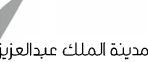


and Sheintuch 1991). The membrane used in the simulation and experimental validation of this work was the electrospun polyvinylidenefluoride-hexafluoropropylene (PVDF-HFP) membrane developed by Lalia et al. (2013, 2017). The membrane is characterized by a pore size and porosity of $0.1 \mu \mathrm{m}$ and $80 \%$, respectively. Subsequently, the equivalent thermophysical properties of the porous membrane (i.e., density, thermal conductivity, and specific heat) stated earlier in Table 1 were evaluated using the permeability (or porosity) weighted average relation.

\section{Heat transfer}

The heat transfer in DCMD can be described in a series of three thermal resistances: (1) convective transfers through the feed boundary layer $\left(q_{\mathrm{f}}\right),(2)$ combined transfer across the membrane $\left(q_{\mathrm{m}}\right)$, and finally (3) convective transfer through the permeate boundary layer $\left(q_{\mathrm{p}}\right)$ (Khayet 2011; Khayet and Matsuura 2011a). The total heat flux across the membrane $\left(q_{\mathrm{m}}\right)$ is attributed to a combination of the conduction $\left(q_{\mathrm{c}}\right)$ and latent heat of evaporation $\left(q_{\mathrm{v}}\right)$ and expressed as:

$q_{\mathrm{m}}=q_{\mathrm{c}}+q_{\mathrm{v}}=h A \Delta T_{\mathrm{m}}$

where $h$ is the membrane heat transfer coefficient. The conduction part is due to the bulk membrane material, while the evaporation takes place in the membrane pores. Taking $\Delta H_{\mathrm{v}}$ to be the enthalpy due to the latent heat of the transmembrane mass flux, it can be written as described by Termpiyakul et al. (2005) as:

$q_{\mathrm{v}}=J^{\prime \prime} \Delta H_{\mathrm{v}}$

$\Delta H_{\mathrm{v}}=1.7535 T_{\mathrm{m}}+2024.3$

The conductive heat flux fraction is described by Fourier heat equation as:

$q_{\mathrm{c}}=-\frac{k_{\mathrm{m}}}{\delta_{\mathrm{m}}}\left(T_{\mathrm{m}, \mathrm{f}}-T_{\mathrm{m}, \mathrm{p}}\right)$

where $k_{\mathrm{m}}$ is the equivalent thermal conductivity of the membrane and is due to the bulk conductivity $\left(k_{\mathrm{b}}\right)$ and the vapor conductivity $\left(k_{\mathrm{g}}\right)$ of the weighted volume average (see Table 1). The subscripts $f$ and $p$ signify the feed and permeate, respectively. Thermal efficiency represents the fraction of the heat used as latent heat of evaporation to the total heat flux of Eq. (10) and is described as:

$\eta=\frac{q_{\mathrm{v}}}{q_{\mathrm{m}}}=\frac{J^{\prime \prime} \Delta H_{\mathrm{m}}}{q_{\mathrm{m}}}$
Fig. 7 Detailed illustration of the temperature polarization phenomenon in a typical DCMD process

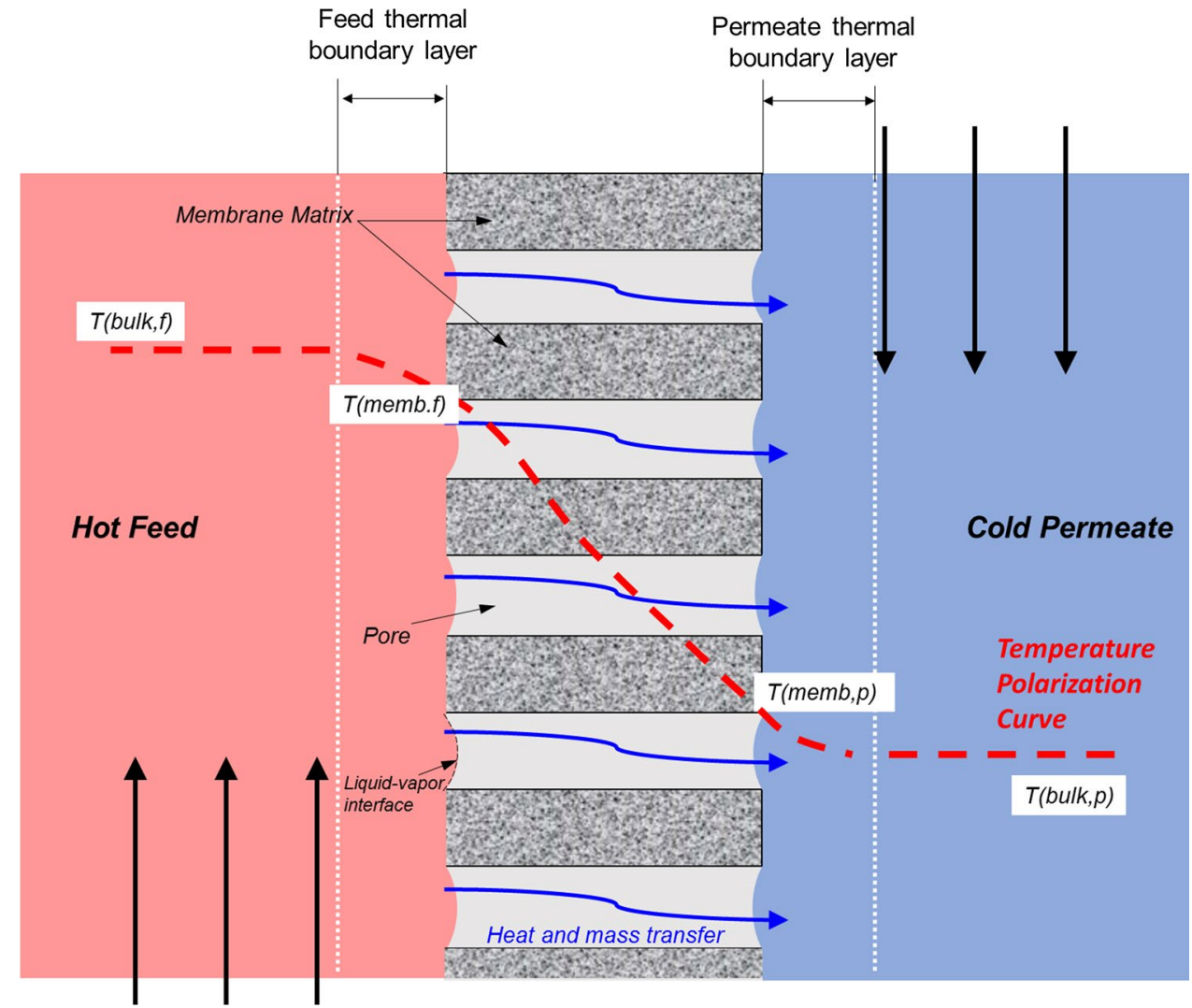


On the other hand, temperature polarization coefficient, TPC (or $\theta$ ) defines the ratio of membrane boundary layer resistance to the total/bulk heat transfer resistance and is expressed using temperature distributions at bulk and membrane surfaces (see Fig. 7) as (Martinez-Diez and VazguezGonzalez 1999; De Záarate et al. 1993):

$\theta=\frac{T_{\mathrm{m}, \mathrm{f}}-T_{\mathrm{m}, \mathrm{p}}}{T_{\mathrm{b}, \mathrm{f}}-T_{\mathrm{b}, \mathrm{p}}}=\frac{\Delta T_{\mathrm{m}}}{\Delta T_{\mathrm{b}}}$

where subscripts $m, f, p$, and $b$ refers to the membrane, feed, permeate, and bulk, respectively.

\section{Results and discussion}

\section{Model validation}

As temperature profile at membrane and bulk surfaces is the most important parameter obtained from the CFD model, an experimental validation of temperature measurement was carried out. The geometry of the DCMD experimental unit used was identical to the CFD model, where two thermal reservoirs each with a peristaltic pump (i.e., feed and permeate) were attached as depicted in Fig. 8a. The DCMD unit was fixed with 24 T-type thermocouples distributed equally at both channels to capture the temperature at both membrane and bulk temperatures (see Fig. 8b). For each

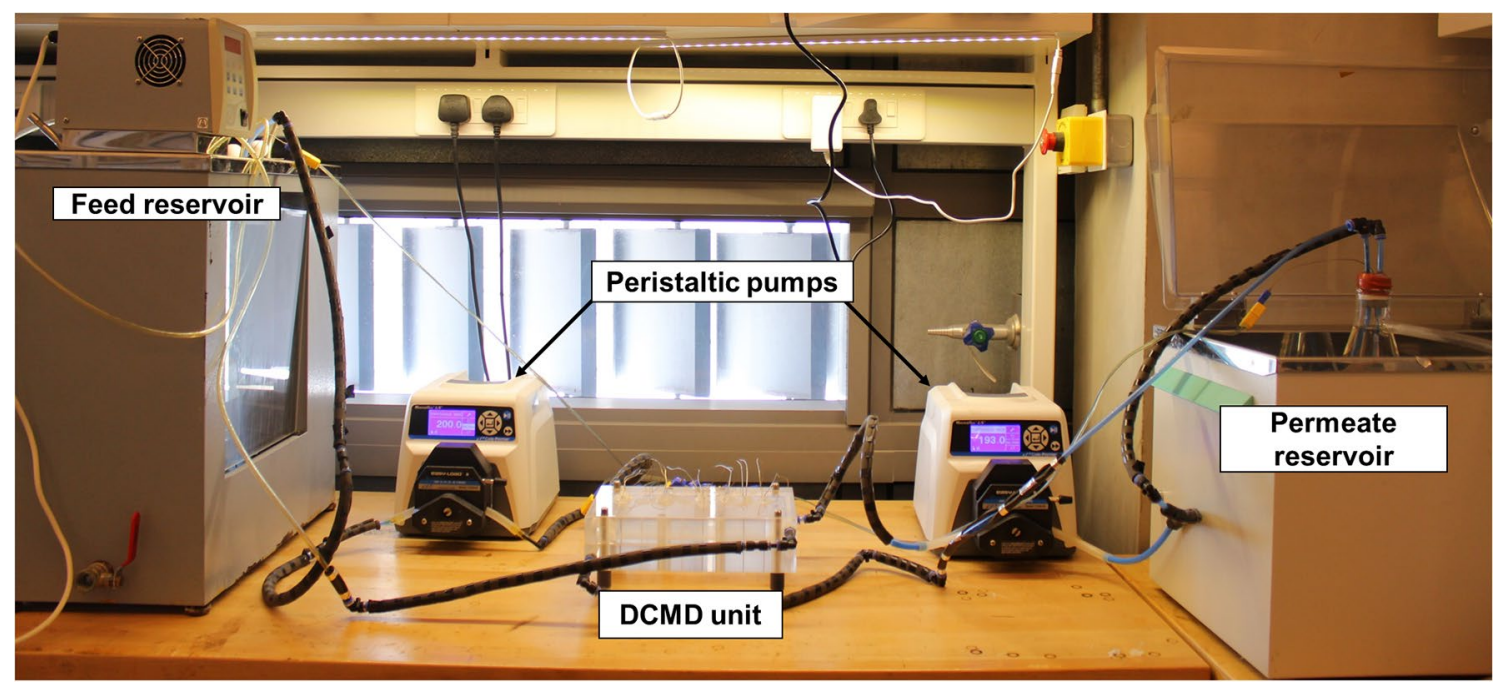

(a)

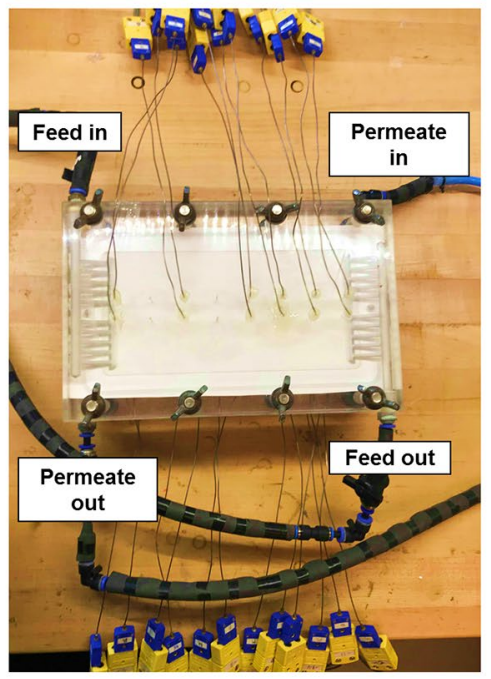

(b)

Fig. 8 Experimental apparatus showing a the full setup, b a top view of the DCMD unit attached with the T-type thermocouples showing the thermocouples placement at bulk and membrane surfaces 

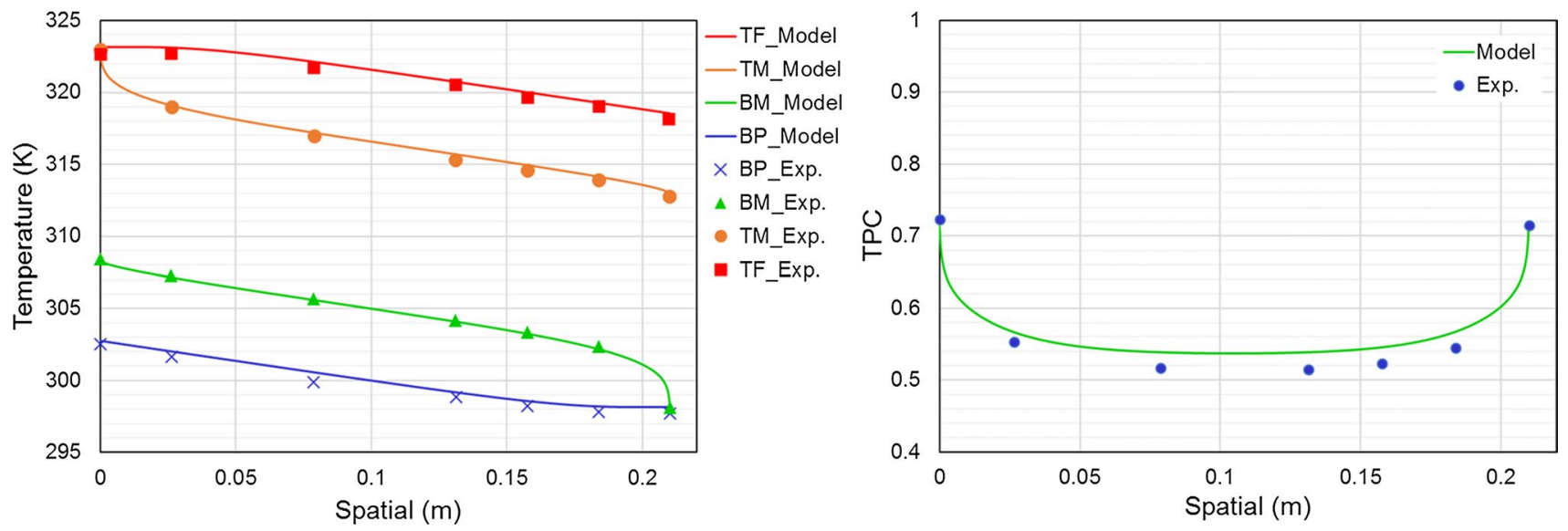

Fig. 9 Validation results of temperature (left) and TPC (right) of both experiments and simulations (T: top, B: bottom, F: feed, M: membrane, and P: permeate)

channel, six of the thermocouples were placed $1 \mathrm{~mm}$ deeper to capture the membrane surface temperature as seen in the zoomed section depicted in Fig. 8c. Electrospun PVDF-HFP membrane developed by Laila et al. $(2013,2017)$ was used in the experiments. Validation was carried out by operating both model and experiment using the same conditions with feed temperature of $50{ }^{\circ} \mathrm{C}$, permeate temperature of $25^{\circ} \mathrm{C}$, and flow velocity of $0.1 \mathrm{~m} / \mathrm{s}$. Figure 9 shows the temperature and TPC values of the twenty-four spatially located thermocouples and their corresponding numerical values. A good agreement between both experimental and numerical results is clearly noticeable.

\section{Effect of spacer material}

Temperature contours of DCMD baseline model, polymeric, and copper spacer-filled model under the same flow conditions (i.e., inlet feed temperature: $75^{\circ} \mathrm{C}$, inlet permeate temperature: $25^{\circ} \mathrm{C}$, inlet flow velocity: $0.1 \mathrm{~m} / \mathrm{s}$ ) are illustrated in Fig. 10. The contours were captured at the channel midway (from $x=0.105 \mathrm{~m}$ to $x=0.115 \mathrm{~m}$ ) for better visualization. These values are well behaved as they are bounded by the imposed boundary conditions. The two channels appear to be semi-isolated, and more so for the spacer-filled model. These results serve as validation of the deployed high-fidelity numerical model. This can be translated to have the highest temperature polarization effect in the DCMD baseline
Fig. 10 Temperature contours $\left({ }^{\circ} \mathrm{C}\right)$ of the DCMD baseline (a), polymer spacer-filled (b), and copper spacer-filled models captured at a 1-cm-long section bounded from $x=0.105 \mathrm{~m}$ to $x=0.115 \mathrm{~m}$

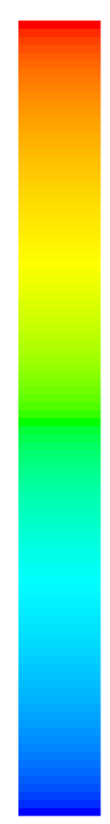

75.00
72.50
70.00
67.50
65.00
62.50
60.00
57.50
55.00
52.50
50.00
47.50
45.00
42.50
40.00
37.50
35.00
32.50
30.00
27.50
25.00

(a) DCMD: Spacer free

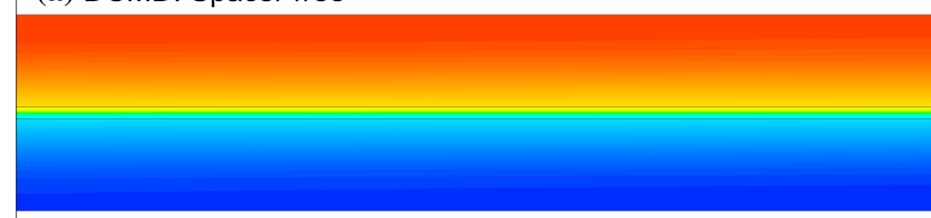

(b) DCMD: Polymer spacer

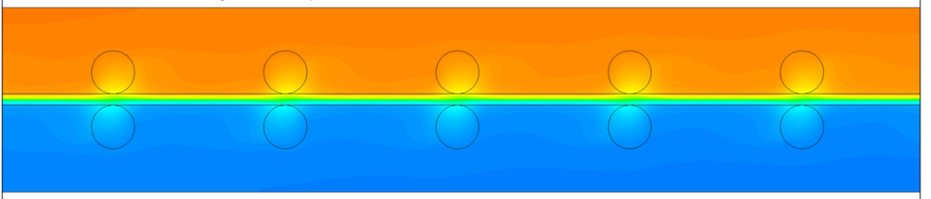

(c) DCMD: Copper spacer

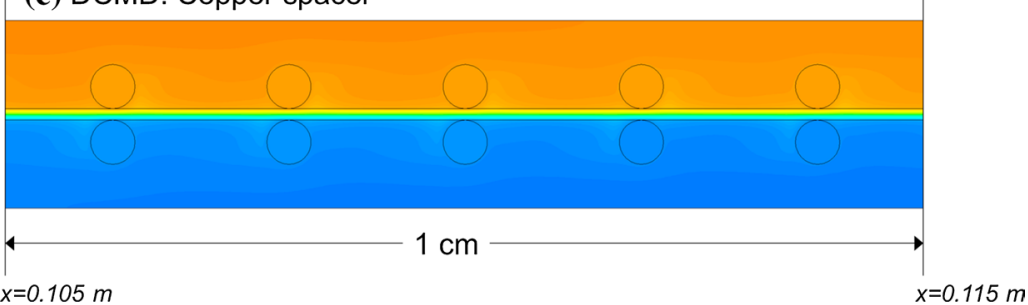




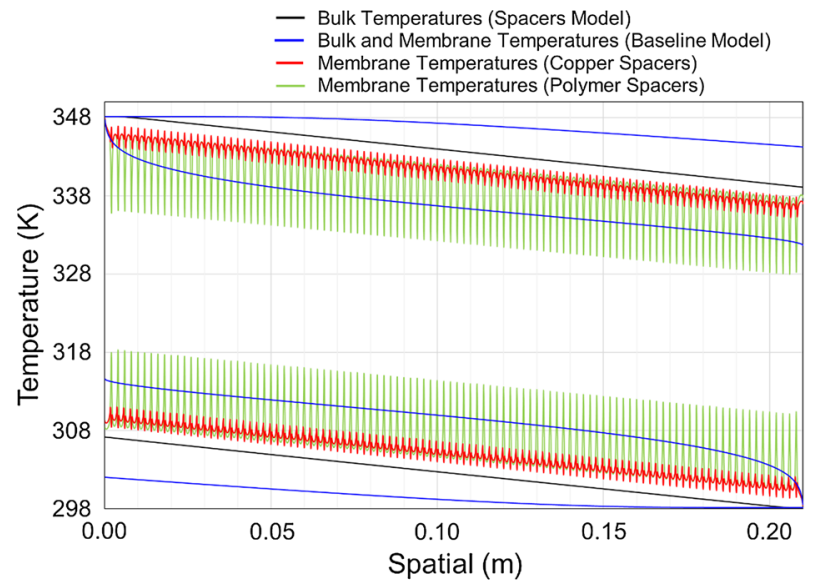

(a)

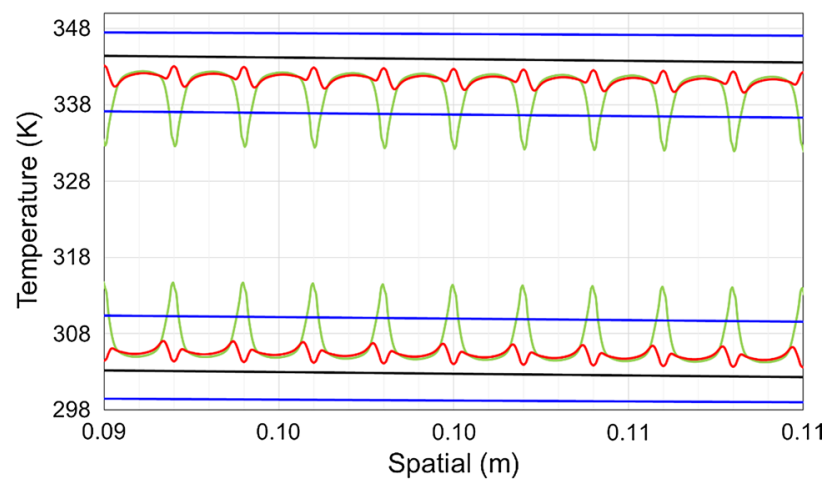

(b)

Fig. 11 Temperature distribution of the conductive/non-conductive spacer-filled DCMD model compared with the baseline model recorded at $\mathbf{a}$ full module length, and $\mathbf{b}$ at a zoomed midway section of $2 \mathrm{~cm}$ length

model compared to both polymeric and copper spacer-filled models. Moreover, copper-based spaced DCMD channels shows lower polarization than that in the polymer-based one. This is because of the higher thermal conductivity of copper than that of the polymer. More precisely, Fig. 11a shows the temperature distributions at the bulk and membrane surfaces of the three different cases. A zoomed temperature distribution of the three models is also shown in Fig. 11b taken from a $2-\mathrm{cm}$ section at a midway distance. Due to the high thermal conductivity of copper spacers, it allowed high heat transfer across the channel depth which is illustrated in the elevated membrane surface temperature at the feed side and thus maintaining a large transmembrane temperature gradient. In contrast, the poor thermal conductivity of the polymeric material leads to a significant reduction in the feed side membrane temperatures and thus thicker thermal boundary layer.

The effect of spacer material on TPC is depicted in Fig. 12. Spaced DCMD configuration of both materials introduces an undulated behavior on the TPC profile.

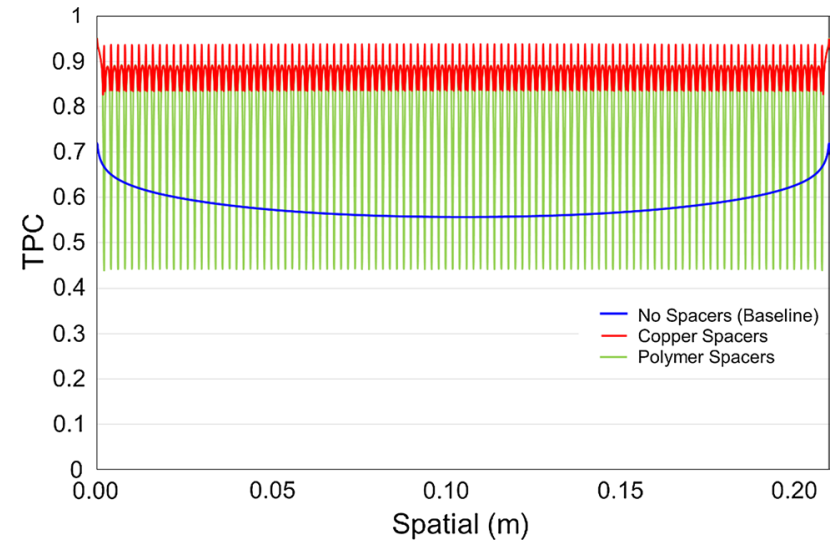

Fig. 12 TPC distribution of the copper and polymer spaced DCMD models compared with the spacer-free baseline model

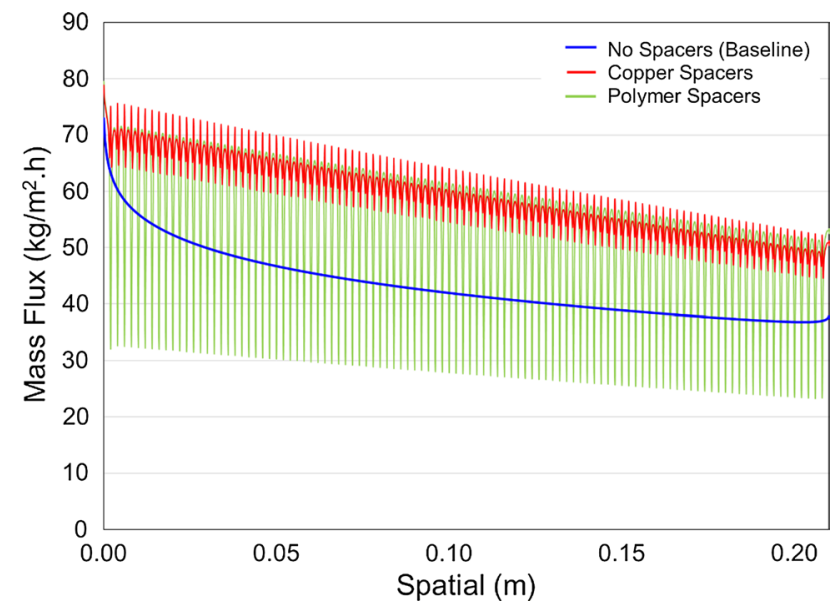

Fig. 13 Mass flux distribution of the copper and polymer spaced DCMD models compared with the spacer-free baseline model

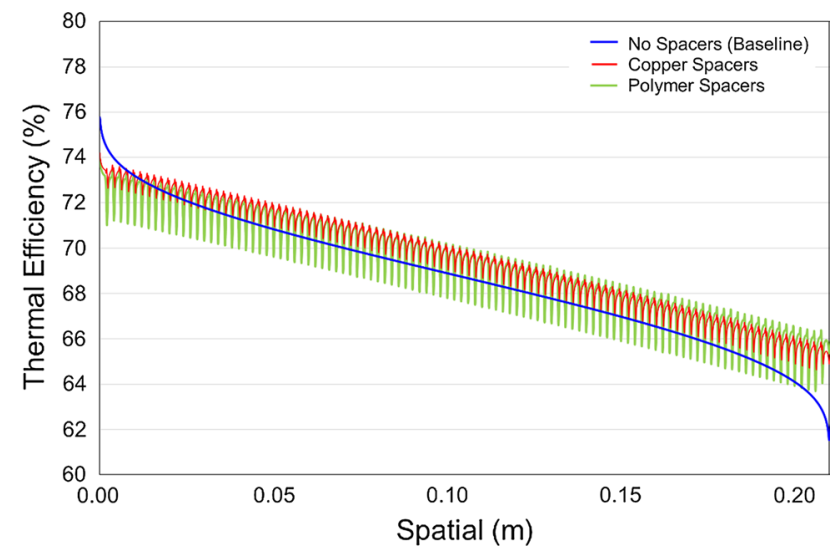

Fig. 14 Thermal efficiency distribution of the copper and polymer spaced DCMD models compared with the spacer-free baseline model 


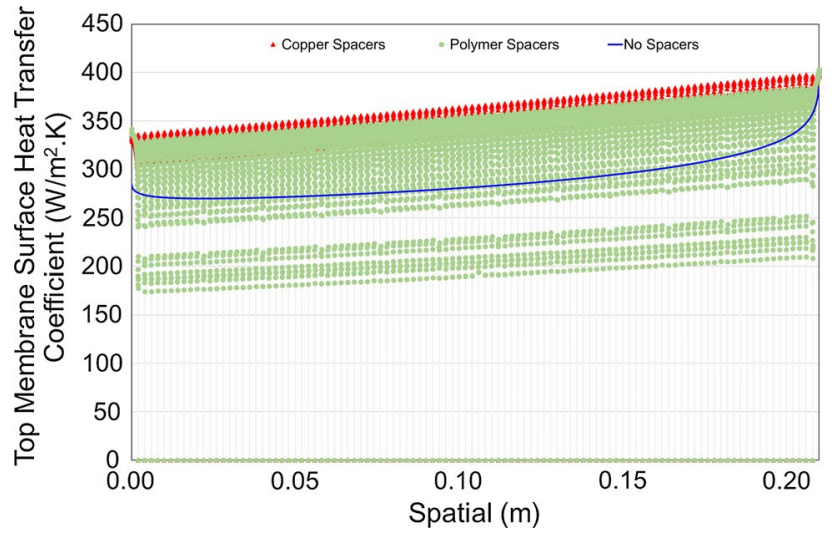

Fig. 15 Top membrane surface heat transfer coefficients of baseline and spacer-filled (polymer and copper) DCMD models

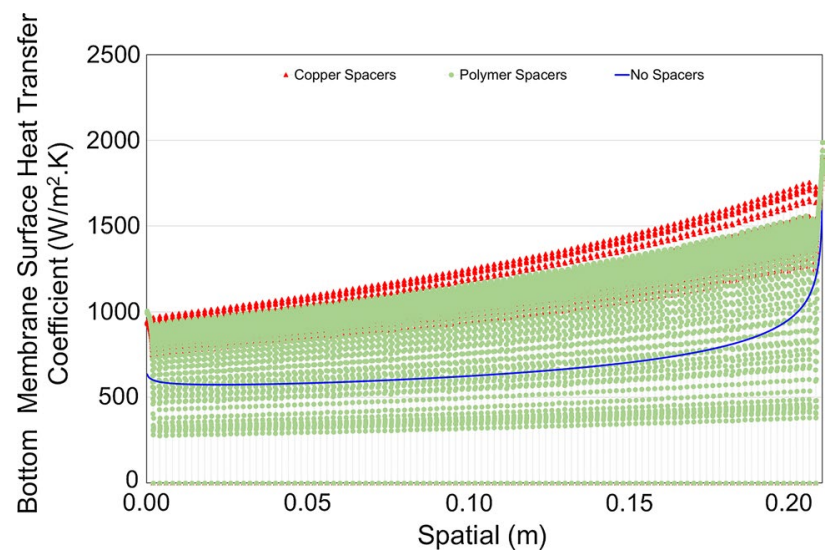

Fig. 16 Bottom membrane surface heat transfer coefficients of baseline and spacer-filled (polymer and copper) DCMD models

However, copper-based spacers show an optimistic undulation effect with average TPC value of 0.876 compared to 0.793 and 0.582 for the polymer-based and spacer-free models, respectively. A highly frequented TPC behavior is observed for the polymeric spaced model due to the high thermal boundary layer resistance across the spacer material, and still, polymer spaced DCMD module shows also in average a lower temperature polarization than the spacer-free DCMD module. Mass flux and thermal efficiency distributions of the three models are displayed in Figs. 13 and 14, respectively. Correspondingly, superior performance is observed for the copper spaced DCMD module reaching an average mass flux of $58.7 \mathrm{~kg} / \mathrm{m}^{2} \mathrm{~h}$ and average thermal efficiency of $69.49 \%$. Polymer spaced module has also shown an elevated average mass flux production of $53.4 \mathrm{~kg} / \mathrm{m}^{2} \mathrm{~h}$ and thermal efficiency of $69.23 \%$. Nevertheless, thermal efficiency shows a negligible influence by the integration of spacer since thermal efficiency is mainly dominated by the membrane properties and feed temperature which were fixed in all cases.

Additionally, distributions of heat transfer coefficient at both top and bottom membrane surfaces of the copper and polymer spaced models compared with the spacer-free baseline model are depicted in Figs. 15 and 16, respectively. Overall, it is noticeable that bottom surface has elevated heat transfer coefficient when compared to the top surface. This can be explained by the conservation of energy across the feed, membrane, and permeate channel. Results also show that copper spaced DCMD led to higher heat transfer coefficient with an average gain of $\sim 19 \%$ at the top membrane surface and $62.5 \%$ at the bottom membrane surface when compared to the baseline. These results are in good agreement with the literature (Katsandri 2017b; Chang et al. 2017). Table 2 quantifies the average values of heat transfer coefficients of both copper and polymer spacer-filled DCMD models with relative gain percentages compared to the baseline spacer-free DCMD model.

\section{Effect of spacer displacement}

Velocity vectors and contours of turbulent kinetic energy at the two different types of spacers distributions (i.e., D1.5 and D3.5) are illustrated in Figs. 17 and 18, respectively. These profiles cover the developed steady flow from a midway region of $1 \mathrm{~cm}$ long bounded from $x=0.105 \mathrm{~m}$ to $x=0.115 \mathrm{~m}$. Velocity vectors show an increase in the local velocity in the area between spacers and bulk walls, while stagnant regions near membrane surface are clearly noticed. In type D1.5, stagnant regions are more pronounced and discontinuity of flow exists at membrane surface as the consequent spacer body seems to be placed within the downstream boundary of the preceding spacer leading to insufficient time and space for the development of vortices behind the upstream. In the other case, however (i.e., D3.5), reattachment of the flow is allowed at membrane surface before the flow goes over the next spacer. Since velocity and turbulence
Table 2 Average heat transfer coefficients at top and bottom membrane surfaces of baseline, copper- and polymer- spaced models

\begin{tabular}{lllll}
\hline Spacers material & \multicolumn{4}{l}{ Surface heat transfer coefficient $\left(\mathrm{W} / \mathrm{m}^{2} \mathrm{~K}\right)$} \\
\cline { 2 - 5 } & Top membrane & Gain $(\%)$ & Bottom membrane & Gain (\%) \\
\hline No spacers (baseline) & 288.94 & - & 680.22 & - \\
Polymer & 323.36 & 11.91 & 975.76 & 43.45 \\
Copper & 343.62 & 18.92 & 1105.31 & 62.49 \\
\hline
\end{tabular}


Fig. 17 Velocity vectors $(\mathrm{m} / \mathrm{s})$ of spacer-filled DCMD models using $1.5 \mathrm{~mm}$ (above) and $3.5 \mathrm{~mm}$ (bottom) spacer displacement running at $\mathrm{Re}=100$ (captured at midway section of $1 \mathrm{~cm}$ length for better visualization)
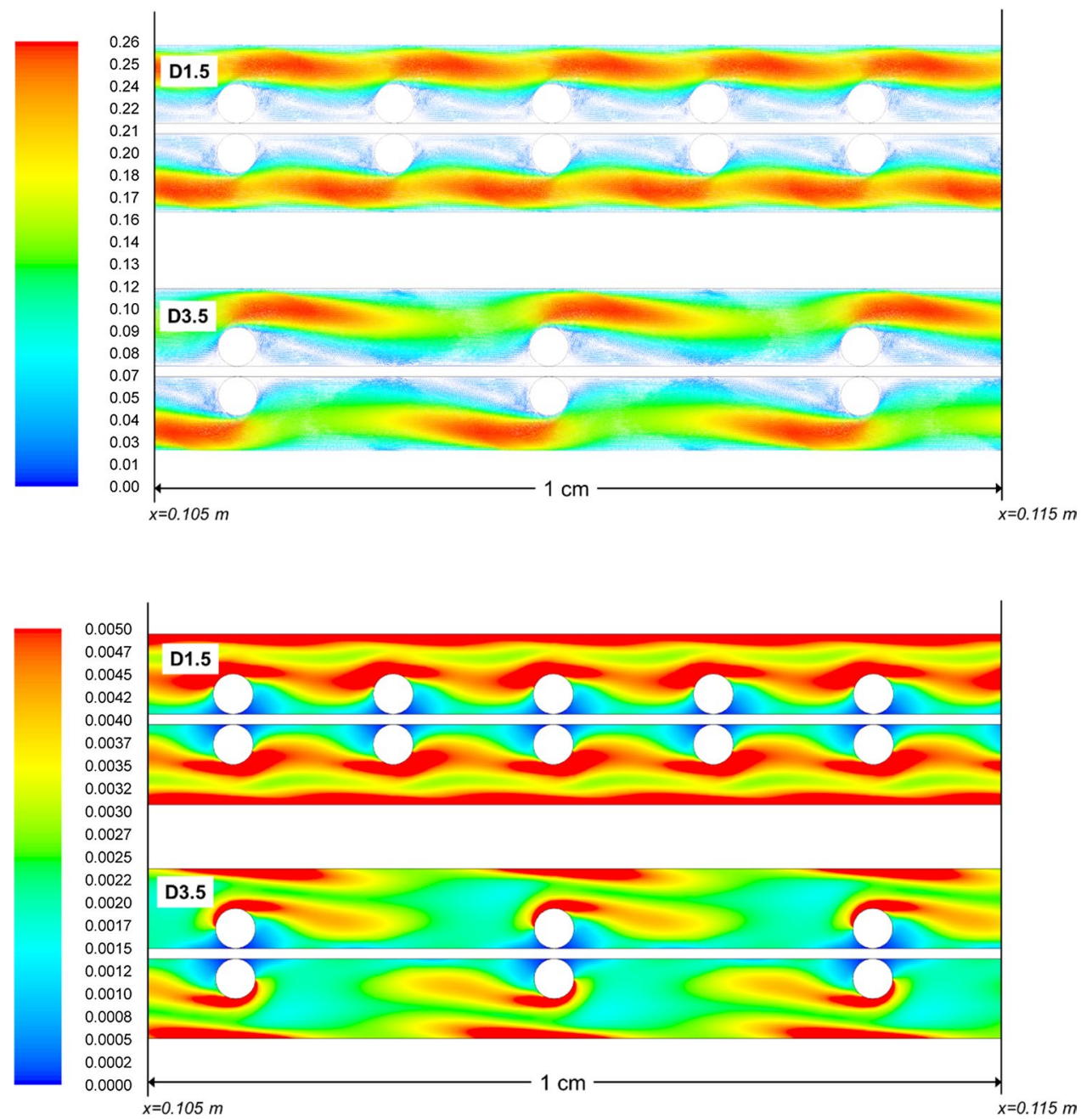

$=0.115 \mathrm{~m}$
Fig. 18 Contours of turbulent kinetic energy $\left(\mathrm{m}^{2} / \mathrm{s}^{2}\right)$ of spacerfilled DCMD models using $1.5 \mathrm{~mm}$ (above) and $3.5 \mathrm{~mm}$ (bottom) spacer displacement running at $R e=100$ (captured at midway section of $1 \mathrm{~cm}$ length for better visualization) are directly related, the same behavior can be noticed in the contours of turbulent kinetic energy in Fig. 18. Regions of turbulence are located near the spacer surfaces, followed by separation of flow and formation of wake region. When the distance between spacers was extended to D3.5, an increase in turbulent kinetic energy is observed at the membrane surface.

Temperature distributions across the DCMD channels for spacer-free (i.e., BL), D1.5, and D3.5 models are presented in Fig. 19. Magnified profile at the midway region (from $x=0.09 \mathrm{~m}$ to $x=0.11 \mathrm{~m}$ ) is presented in Fig. 19b. A less fluctuating profile is noticed for type D3.5 compared to D1.5. Nevertheless, both types seem to be close to each other making higher transmembrane temperature difference than the spacer-free DCMD model. Similarly, slightly lower oscillation of TPC distribution of D3.5 compared to D1.5 is observed in Fig. 20. This is translated to an average TPC value of 0.879 and 0.877 for D3.5 and D1.5, respectively. Profiles of mass flux and thermal efficiency showing comparable performance of both cases (D1.5 and D3.5) are also displayed in Figs. 21 and 22, respectively.
A negligible gain was observed in type D3.5 with an average mass flux of $59 \mathrm{~kg} / \mathrm{m}^{2} \mathrm{~h}$ and thermal efficiency of $69.52 \%$ compared to $58.77 \mathrm{~kg} / \mathrm{m}^{2} \mathrm{~h}$ and $69.50 \%$ for $\mathrm{D} 1.5$. Accordingly, transmembrane heat flux of $3864.29 \mathrm{~W}$ and $3878.5 \mathrm{~W}$ was recorded for D1.5 and D3.5, respectively. Table 3 provides a quantitative summary of the role of spacer integration on the average DCMD performance metrics at the studied spacers material and displacement.

\section{Concentration polarization}

Results of the concentration polarization at feed channel of the BL and D1.5 models are depicted in Fig. 23. It shows the line spatial distributions of the salinity starting from the entry and moving toward the exit. The entry condition was assumed at $3 \% \mathrm{NaCl}$ concentration which is the fixed value of the channel bulk wall $(y=0.001 \mathrm{~m})$. However, the concentration at the membrane boundary layer increases asymptotically starting from $3 \%$ and exceeding the double value at the exit and reaching $7.5 \%$ while averaging $7 \%$ for the baseline model. As the layer is closer to the membrane surface, their 


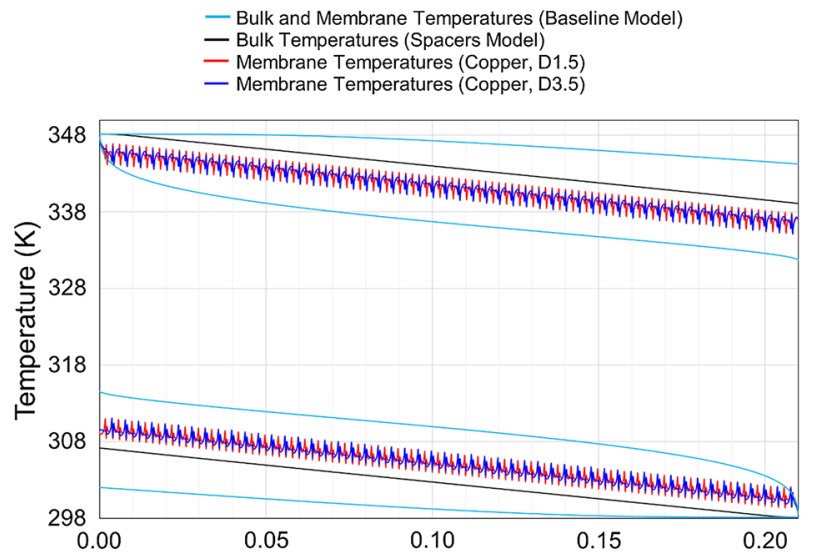

(a)

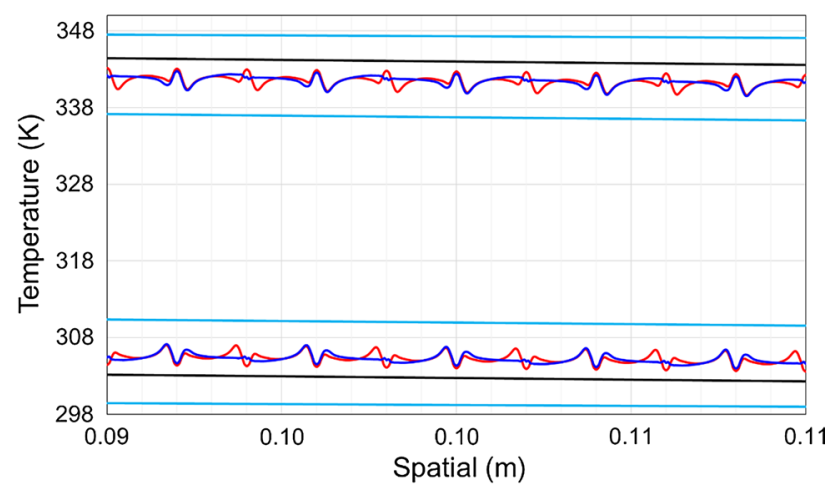

(b)

Fig. 19 Temperature distribution of DCMD spacer-filled model of type D1.5 and D3.5 compared with the spacer-free BL model recorded at $\mathbf{a}$ full module length, and $\mathbf{b}$ at a zoomed midway section of $2 \mathrm{~cm}$ length

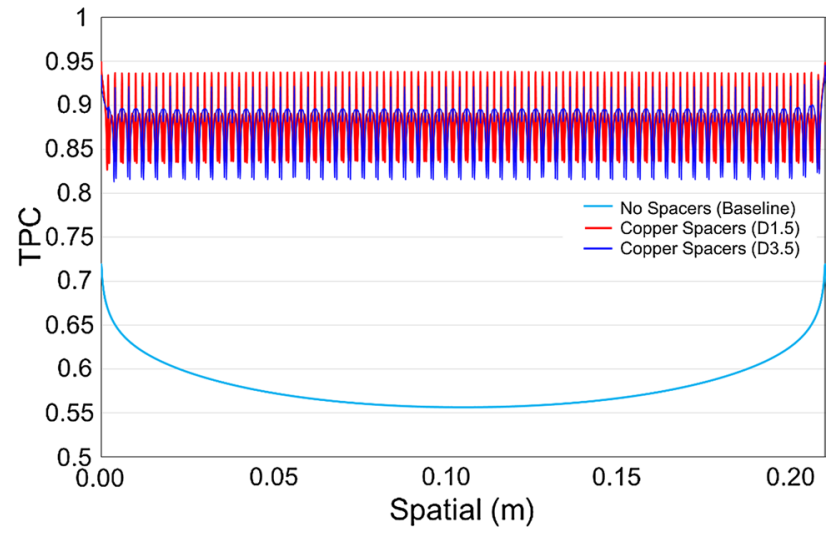

Fig. 20 TPC distribution of DCMD model spaced with copper at different displacement (D1.5 and D3.5) compared with the BL model

brine concentration is exasperated. The concentration boundary layer is more clearly observed by the vertical lines of the

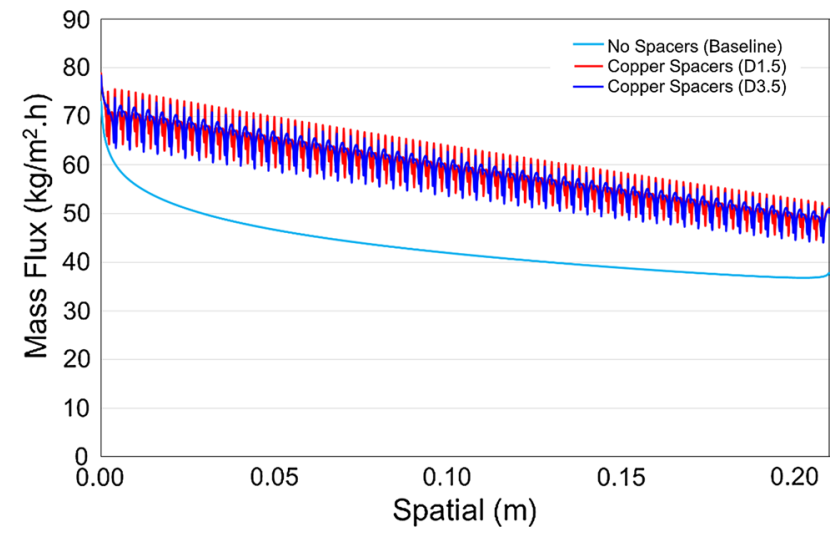

Fig. 21 Mass flux distribution of DCMD model spaced with copper at different displacement (D1.5 and D3.5) compared with the BL model

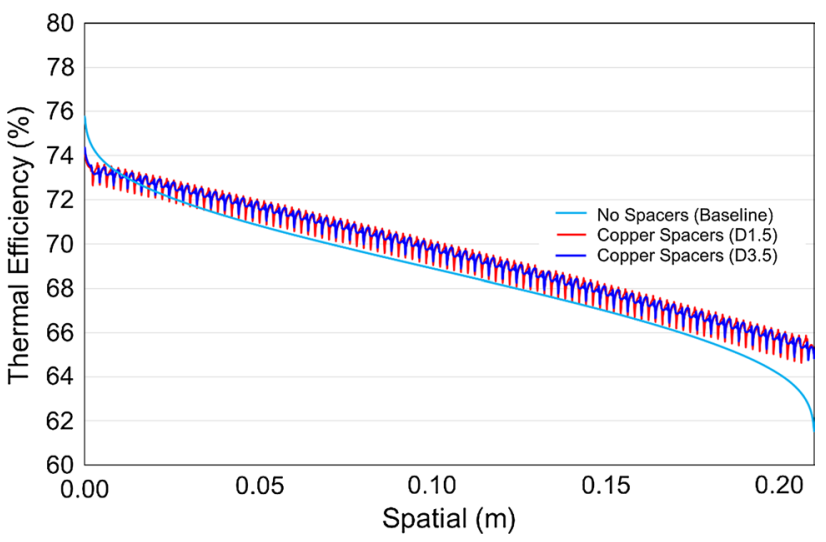

Fig. 22 Thermal efficiency distribution of DCMD model spaced with copper at different displacement (D1.5 and D3.5) compared with the BL model

baseline model than the spacer filled, and an increase in the surface value and layer thickness is obvious due to the flow and transportation of the fresh water specie. One needs to recall Eqs. 7 and 8 which influence the magnitude of the driving pressure on the brine side as any increase in the concentration would compromise such values. Therefore, attainment of $7 \%$ concentration would decrease the water activity from $a_{\mathrm{w}}=0.976$ value to $a_{\mathrm{w}}=0.916$ value (i.e., reduction of $6 \%$ in pressure), and hence, in the transported fresh flux by relying on Eq. 5 through which this flux is nearly proportional to it, should one relax the dependency on the mass flux coefficient without any loss of generality. It is clear from Fig. 23 (right) 
Table 3 DCMD quantitative metrics and comparison of polymer- and copper- spaced models using $1.5 \mathrm{~mm}$ and $3.5 \mathrm{~mm}$ spacers displacement

\begin{tabular}{|c|c|c|c|c|c|c|c|c|c|}
\hline Spacers material & $\begin{array}{l}\text { Spacers } \\
\text { displacement } \\
(\mathrm{mm})\end{array}$ & Avg. TPC & Gain (\%) & $\begin{array}{l}\text { Total sensible } \\
\text { heat flux (W) }\end{array}$ & Gain $(\%)$ & $\begin{array}{l}\text { Avg. mass } \\
\text { flux }(\mathrm{kg} / \\
\left.\mathrm{m}^{2} \mathrm{~h}\right)\end{array}$ & Gain (\%) & $\begin{array}{l}\text { Avg. thermal } \\
\text { efficiency }(\%)\end{array}$ & Gain (\%) \\
\hline No spacers (baseline) & - & 0.582 & - & 2949.09 & - & 43.30 & - & 68.69 & - \\
\hline \multirow[t]{2}{*}{ Polymer } & 1.5 & 0.793 & 36.21 & 3544.23 & 20.18 & 53.40 & 23.32 & 69.23 & 0.79 \\
\hline & 3.5 & 0.839 & 44.10 & 3721.95 & 26.21 & 55.99 & 29.30 & 69.30 & 0.90 \\
\hline \multirow[t]{2}{*}{ Copper } & 1.5 & 0.877 & 50.56 & 3864.29 & 31.03 & 58.77 & 35.70 & 69.50 & 1.18 \\
\hline & 3.5 & 0.879 & 50.92 & 3878.50 & 31.52 & 59.00 & 36.24 & 69.52 & 1.21 \\
\hline
\end{tabular}
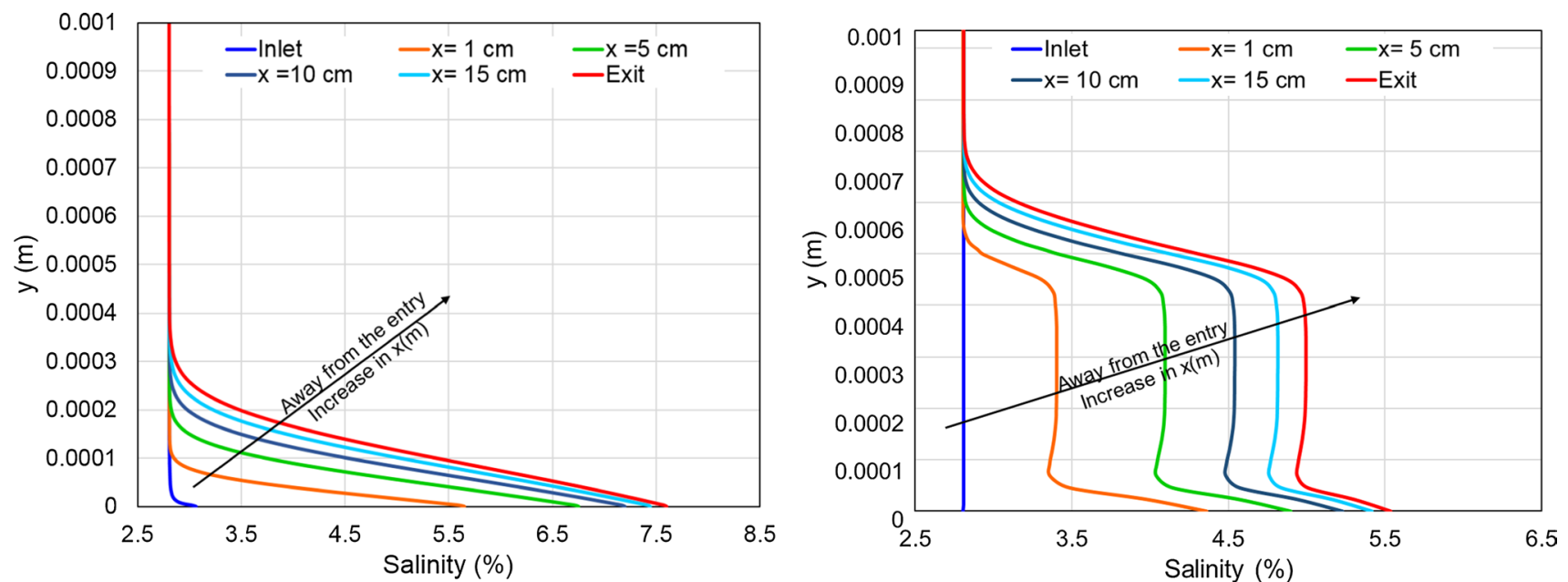

Fig. 23 Vertical distributions of water salinity and their boundary layer growth along the length of the feed channel of the BL spacer-free (left) and the D.15 spacer-filled (right) DCMD models

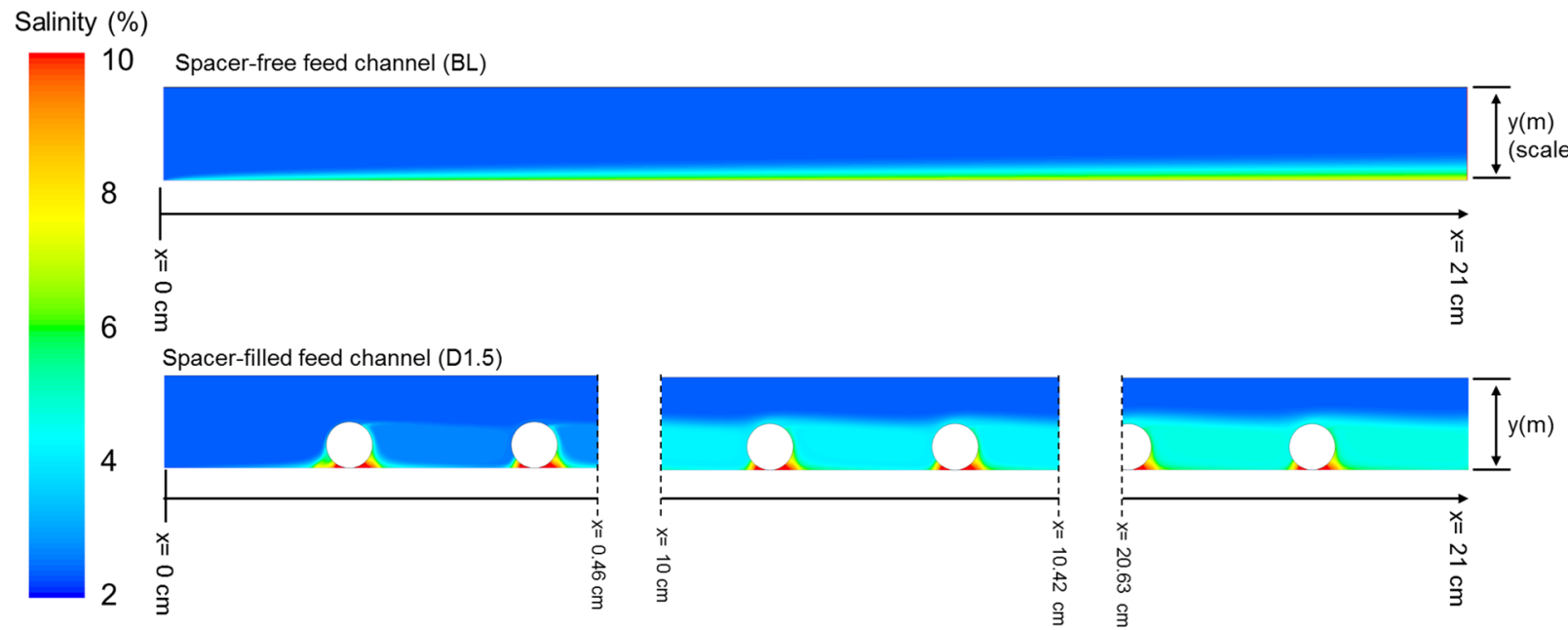

Fig. 24 Feed channel salinity contours showing the concentration polarization effect of BL (top) and D1.5 (bottom) models 
that the exit salinity at the membrane surface drops from $7.5 \%$ for the BL to $5.5 \%$ for D1.5. Contours of salinity for the spacer-free and spacer-filled feed channels are also depicted in Fig. 24. Although areas below spacers are highly concentrated, average salinity at the membrane wall has reduced from 7 to $6 \%$ when D1.5 spacers are integrated. This would enhance the average water activity reaching 0.93 . As a result, the role of spacer in mixing the flow and mitigating the development of concentration polarization is becoming more evident.

\section{Conclusion}

In this work, high fidelity validated CFD modeling is carried out to assess the performance of DCMD with spacer-filled channels. The model simulated different spacers material (i.e., conductive vs. non-conductive) and different spacers displacement and results are compared to the baseline DCMD with free channels. The results are shown in terms of bulk and membrane surface temperature profiles, temperature polarization coefficient (TPC), mass flux, heat flux, thermal efficiency, and heat transfer coefficient at membrane surfaces. The integration of copper spacers led to a superior DCMD performance with TPC of 0.88 , average mass flux of $58.8 \mathrm{~kg} / \mathrm{m}^{2} \mathrm{~h}$, and average thermal efficiency of $69.5 \%$. Polymer spacers also tend to increase the performance but with lower trends having a TPC value of 0.79 , average mass flux of $56 \mathrm{~kg} / \mathrm{m}^{2} \mathrm{~h}$, and average thermal efficiency of $69.2 \%$. On the other hand, increasing the distance between spacer filaments from 1.5 to $3.5 \mathrm{~mm}$ seems to be insufficient to show a noticeable gain in the DCMD performance. Finally, spacer has strong influence on the naturally developed concentration polarization that shows to reduce the fresh flux by stipulated magnitude near $6 \%$. Depending on the flow condition recovering, fresh flux loss with proper integration of the spacers is very possible. In summary, using conductive-based spacers materials could improve the performance more profoundly than changing the spacers orientation or displacement and mitigating concentration development and fresh flux restriction that may cause membrane fouling.

Acknowledgements The authors would like to acknowledge the support of Khalifa University of Science and Technology, Masdar City Campus, that enables them to carry out this work. Funding was provided by Khalifa University of Science and Technology (Grant No. CEMAT20018)

\section{Compliance with ethical standards}

Conflict of interest The authors declare that they have no conflict of interest.

Open Access This article is licensed under a Creative Commons Attribution 4.0 International License, which permits use, sharing, adaptation, distribution and reproduction in any medium or format, as long as you give appropriate credit to the original author(s) and the source, provide a link to the Creative Commons licence, and indicate if changes were made. The images or other third party material in this article are included in the article's Creative Commons licence, unless indicated otherwise in a credit line to the material. If material is not included in the article's Creative Commons licence and your intended use is not permitted by statutory regulation or exceeds the permitted use, you will need to obtain permission directly from the copyright holder. To view a copy of this licence, visit http://creativecommons.org/licenses/by/4.0/.

\section{References}

Abid HS, Johnson DJ, Hashaikeh R, Hilal N (2017a) A review of efforts to reduce membrane fouling by control of feed spacer characteristics. Desalination 420:384-402

Abid HS, Lalia BS, Bertoncello P, Hashaikeh R, Clifford B, Gethin DT, Hilal N (2017b) Electrically conductive spacers for selfcleaning membrane surfaces via periodic electrolysis. Desalination 416:16-23

Ahmed F, Kadi KE, Hashaikeh R, Janajreh I (2017) Low energy membrane distillation: a numerical study on the role of conductive spacers. Energy Procedia 142:4056-4063

Albeirutty M, Turkmen N, Al-Sharif S, Bouguecha S, Malik A, Faruki O, Cipollina A, Ciofalo M, Micale G (2018) An experimental study for the characterization of fluid dynamics and heat transport within the spacer-filled channels of membrane distillation modules. Desalination 430:136-146

Al-Sharif S, Albeirutty M, Cipollina A, Micale G (2013) Modelling flow and heat transfer in spacer-filled membrane distillation channels using open source CFD code. Desalination 311:103-112

Araújo PA, Kruithof JC, Van Loosdrecht MCM, Vrouwenvelder JS (2012) The potential of standard and modified feed spacers for biofouling control. J Membr Sci 403-404:58-70

Ashoor BB, Mansour S, Giwa A, Dufour V, Hasan SW (2016) Principles and applications of direct contact membrane distillation (DCMD): a comprehensive review. Desalination 398:222-246

Baek Y, Yoon H, Shim S, Choi J, Yoon J (2014) Electroconductive feed spacer as a tool for biofouling control in a membrane system for water treatment. Environ Sci Technol Lett 1(2):179-184

Blackshaw GL (1979) Elementary principles of chemical processes by Richard M. Felder and Ronald W. Rousseau, Wiley (1978). AIChE J 25(2):382

Chang H, Hsu J-A, Chang C-L, Ho C-D (2015) CFD simulation of direct contact membrane distillation modules with rough surface channels. Energy Procedia 75:3083-3090

Chang H, Hsu J-A, Chang C-L, Ho C-D, Cheng T-W (2017) Simulation study of transfer characteristics for spacer-filled membrane distillation desalination modules. Appl Energy 185:2045-2057

Chen T-C, Ho C-D, Yeh H-M (2009) Theoretical modeling and experimental analysis of direct contact membrane distillation. J Membr Sci 330(1):279-287

De Záarate JMO, Velázquez A, Peña L, Mengual JI (1993) Influence of temperature polarization on separation by membrane distillation. Sep Sci Technol 28(7):1421-1436

Elias-Kohav T, Sheintuch M (1991) Steady-state diffusion and reactions in catalytic fractal porous media. Chem Eng Sci 46(11):2787-2798

Habimana O, Semião AJC, Casey E (2014) The role of cell-surface interactions in bacterial initial adhesion and consequent biofilm formation on nanofiltration/reverse osmosis membranes. J Membr Sci 454:82-96

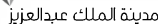

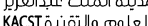


Hagedorn A, Fieg G, Winter D, Koschikowski J, Grabowski A, Mann T (2017) Membrane and spacer evaluation with respect to future module design in membrane distillation. Desalination 413:154-167

Hausman R (2011) Development of low-biofouling polypropylene feed spacers for reverse osmosis, $\mathrm{p} 132$

Huffman E (2014) Water resources management: sector results profile. The World Bank Group, Washington, DC

Iguchi CY, dos Santos WN, Gregorio R (2007) Determination of thermal properties of pyroelectric polymers, copolymers and blends by the laser flash technique. Polym Test 26(6):788-792

Janajreh I, Suwwan D (2014) Numerical simulation of direct contact membrane distillation (DCMD): II, pp 21-32, International Journal of Engineering Research and Innovation, Florida

Janajreh I, El Kadi K, Hashaikeh R, Ahmed R (2017a) Numerical investigation of air gap membrane distillation (AGMD): seeking optimal performance. Desalination 424:122-130

Janajreh I, Suwwan D, Hashaikeh R (2017b) Assessment of direct contact membrane distillation under different configurations, velocities and membrane properties. Appl Energy 185:2058-2073

Janajreh I, El Kadi K, Al Hammadie N, Hashaikeh R (2017c) Direct contact membrane distillation: the role of membrane porosity. Desalin Water Treat 100:258-267

Katsandri A (2017a) A theoretical analysis of a spacer filled flat plate membrane distillation modules using CFD: part I: velocity and shear stress analysis. Desalination 408:145-165

Katsandri A (2017b) A theoretical analysis of a spacer filled flat plate membrane distillation modules using CFD: part II: temperature polarisation analysis. Desalination 408:166-180

Khayet M (2011) Membranes and theoretical modeling of membrane distillation: a review. Adv Colloid Interface Sci 164:56-88

Khayet M, Matsuura T (2011a) Membrane distillation. Elsevier, Amsterdam, pp 249-293

Khayet M, Matsuura T (2011b) Membrane distillation. Elsevier, Amsterdam, pp 227-247

Lalia BS, Guillen-Burrieza E, Arafat HA, Hashaikeh R (2013) Fabrication and characterization of polyvinylidenefluoride-co-hexafluoropropylene (PVDF-HFP) electrospun membranes for direct contact membrane distillation. J Membr Sci 428:104-115

Lalia BS, Janajreh I, Hashaikeh R (2017) A facile approach to fabricate superhydrophobic membranes with low contact angle hysteresis. J Membr Sci 539:144-151

Lawson KW, Lloyd DR (1997) Review: membrane distillation. J Membr Sci 124:1-25

Martínez L, Rodríguez-Maroto JM (2006) Characterization of membrane distillation modules and analysis of mass flux enhancement by channel spacers. J Membr Sci 274(1):123-137

Martinez-Diez L, Vazguez-Gonzalez MI (1999) Temperature and concentration polarization in membrane distillation of aqueous salt solutions. J Membr Sci 156:265-273

Martínez-Díez L, Vázquez-González MI, Florido-Díaz FJ (1998) Study of membrane distillation using channel spacers. J Membr Sci 144(1):45-56

Orfi J, Loussif N (2010) Modeling of a membrane distillation unit for desalination. In: Urbonien IA (ed) Desalination: methods, cost and technology. Nova science Publishers, Inc.

Phattaranawik J, Jiraratananon R, Fane AG, Halim C (2001) Mass flux enhancement using spacer filled channels in direct contact membrane distillation. J Membr Sci 187(1):193-201
Popović S, Jovičević D, Muhadinović M, Milanović S, Tekić MN (2013) Intensification of microfiltration using a blade-type turbulence promoter. J Membr Sci 425-426:113-120

Razmjou A, Arifin E, Dong G, Mansouri J, Chen V (2012) Superhydrophobic modification of $\mathrm{TiO}_{2}$ nanocomposite PVDF membranes for applications in membrane distillation. J Membr Sci 415-416:850-863

Richard H, Tilak G, Escobar IC (2009) Development of low-biofouling polypropylene feedspacers for reverse osmosis. J Appl Polym Sci 114(5):3068-3073

Ronen A, Lerman S, Ramon GZ, Dosoretz CG (2015) Experimental characterization and numerical simulation of the anti-biofuling activity of nanosilver-modified feed spacers in membrane filtration. J Membr Sci 475:320-329

Seo J, Kim YM, Kim JH (2017) Spacer optimization strategy for direct contact membrane distillation: shapes, configurations, diameters, and numbers of spacer filaments. Desalination 417:9-18

Shakaib M, Hasani SMF, Ahmed I, Yunus RM (2012) A CFD study on the effect of spacer orientation on temperature polarization in membrane distillation modules. Desalination 284:332-340

Sharqawy H, Lienhard VJ, Zubair SM (2010) The thermophysical properties of seawater: a review of existing correlations and data. Desalin Water Treat 16:354-380

Taamneh Y, Bataineh K (2017) Improving the performance of direct contact membrane distillation utilizing spacer-filled channel. Desalination 408:25-35

Tamburini A, Renda M, Cipollina A, Micale G, Ciofalo M (2016) Investigation of heat transfer in spacer-filled channels by experiments and direct numerical simulations. Int J Heat Mass Transf 93:1190-1205

Termpiyakul P, Jiraratananon R, Srisurichan S (2005) Heat and mass transfer characteristics of a direct contact membrane distillation process for desalination. Desalination 177(1):133-141

Wang Z, Lin S (2017) The impact of low-surface-energy functional groups on oil fouling resistance in membrane distillation. J Membr Sci 527:68-77

Warsinger DM, Swaminathan J, Guillen-Burrieza E, Arafat HA, Lienhard V (2015) Scaling and fouling in membrane distillation for desalination applications: a review. Desalination 356:294-313

Winter D (2014) Membrane distillation a thermodynamic, technological and economic analysis. Shaker Verlag, Filderstadt

Yang H-L, Lin JC-T, Huang C (2009) Application of nanosilver surface modification to RO membrane and spacer for mitigating biofouling in seawater desalination. Water Res 43(15):3777-3786

Yang X, Yu H, Wang R, Fane AG (2012) Analysis of the effect of turbulence promoters in hollow fiber membrane distillation modules by computational fluid dynamic (CFD) simulations. J Membr Sci 415-416:758-769

Publisher's Note Springer Nature remains neutral with regard to jurisdictional claims in published maps and institutional affiliations. 